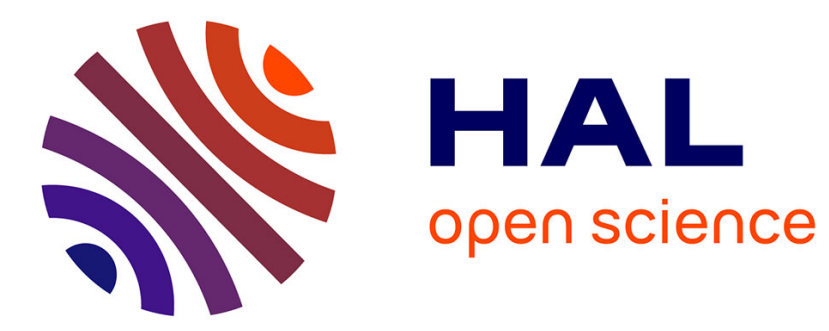

\title{
Manches de patères ornés en céramique de Lezoux Hugues Vertet
}

\section{To cite this version:}

Hugues Vertet. Manches de patères ornés en céramique de Lezoux. Gallia - Fouilles et monuments archéologiques en France métropolitaine, 1972, 30 (1), pp.5-40. 10.3406/galia.1972.2594 . hal01934869

\section{HAL Id: hal-01934869 \\ https://hal.science/hal-01934869}

Submitted on 11 Mar 2020

HAL is a multi-disciplinary open access archive for the deposit and dissemination of scientific research documents, whether they are published or not. The documents may come from teaching and research institutions in France or abroad, or from public or private research centers.
L'archive ouverte pluridisciplinaire $\mathbf{H A L}$, est destinée au dépôt et à la diffusion de documents scientifiques de niveau recherche, publiés ou non, émanant des établissements d'enseignement et de recherche français ou étrangers, des laboratoires publics ou privés.

\section{(이) $\$$}

Distributed under a Creative Commons Attribution - NonCommercial - NoDerivatives| 4.0 


\title{
MANCHES DE PATÈRES ORNÉS EN CÉRAMIQUE DE LEZOUX
}

\author{
par Hugues VERTET
}

l.article de suzanne Tassinari sur les pateres a manche orne, en métal, paru récemment

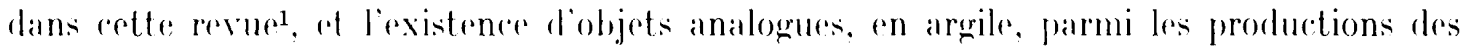
ateliers de lazoux. Viehy at Toulon-sur-Allier, nous ont incité a présenter ce premier repertoire. Cone enquete plus complete permettra de réunir une nouvelle liste d'objets, de provenanees diverses, of de tirer des conclusions plus générales sur cotte catégorie d'objets dont J. Dérhelette avait déjà publié en 1904, quelques-uns provenant de Lezoux².

Pour simplifier nos dereriptions. nous aroms sehématise le manche de palire plat. dont il s'agil ici (fig. 1). Nous appelons:

la hase (a) : la partie rollee conl re la panse du récipient. Elle se divise en deux branches (b) qui portent une. deux cu lrois exroissances : les epaulements (r):

la tige 'd : la parlie centrale allongrée. normalement temue on main par l'ulilisaleur;

l'exlrémité fe: la partie, presque loujours renflée, qui termine le manche. Souvent cette extrémite est en forme d'anneau anneau terminal et percée d'un trou de suspension.

Pour une rédaction plus rapide. nous avons résume par les iniliales J.l) of osill. les ourrages

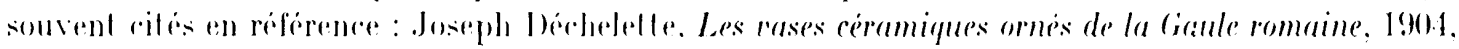

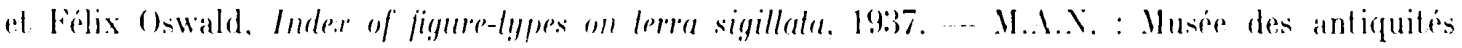
nationales, is saint-(iermain-en-Jaye.

\section{RÉPERTOHRE DES MANCHES}

1. -.. Officine de Toulon-anr-.llier" inseription manuserite : "Toulon. Lary, rollection Bert rand ", Musie de Voulins, $n^{0}$ ancien 12:27 : pl. 2 a. b.

Protol ype de manche' ; la branche droile est cassée : longe de la lige : 109 mm : large. de l'extrémite : $47 \mathrm{~mm}$ : larg. de la demi-base : $49 \mathrm{~mm}$; ćpaiss. : 14 a $16 \mathrm{~mm}$.

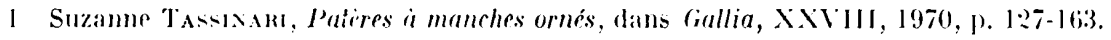

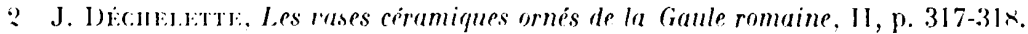

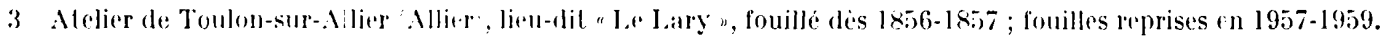

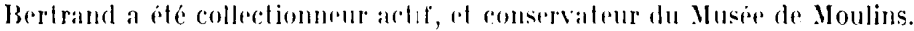

4 I. "xplication du lerme protolype est domner plus loin, r. "Fabrication". 


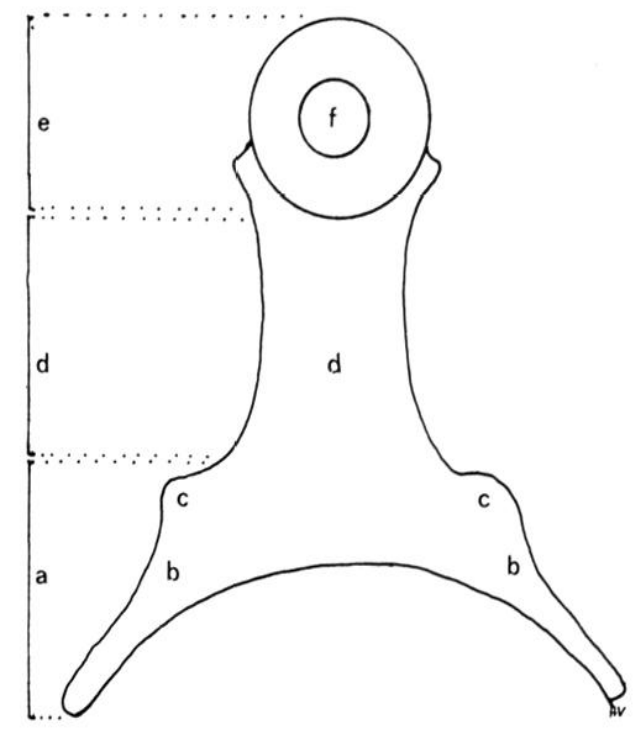

I Schima du manche dre patiere plat, a : la base; b : les branches ; $c$ : les epaulements; 1) : la lige: e : ratremite (ici, annean terminal:; f : lrou de suspension.

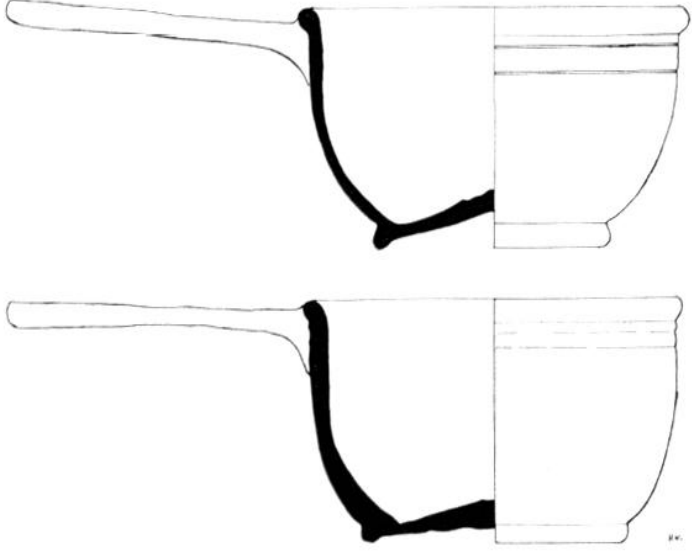

$\because$ Protil des paferes complites di Muser de CllormontFirrand. a: $\left.n^{\circ} !\right) ; b: n^{\circ} 13$.

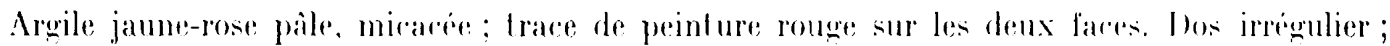

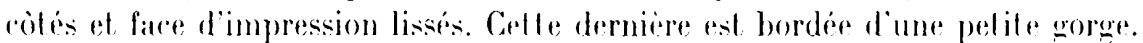

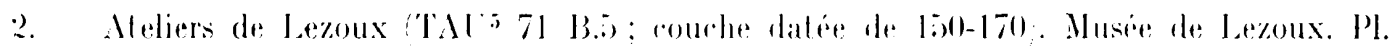
$\therefore$ ed.

Prototype de manche : la base manque : lone. da lesson : $72 \mathrm{~mm}$ : lare. : 19 mm ; epaiss. : 1.1-16i mm.

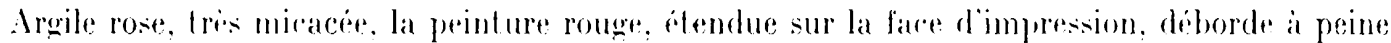
sur le dos, qui est tris irregulier ; rote et face d'impression lisses. Cette derniere porte. sur toute

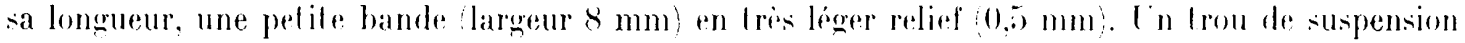
est percé de fagon lres sommaire aver de grosies bavures. Le polier n'a pas roupe l'extrémite du manche perpendiculairement à l'axe. re qui lait que l'extrémitr wanche du manche pol plus courte que la droite.

3. - . Ateliers du Centre de la Gaule (Vichy probablemenl, Musie de Monlins, sans origine. l'. : i. b.

fragment de moule, il manque l'exlrémile el la branche droile: long. conservere : sx mm ; ipaiss. de l'argile: : 7 il $10 \mathrm{~mm}$.

Argile rose.

De lanneau lerminal, il ne subsiste que la lare dine double monlure circulaire. Ia tige est aussi longée par une double moulure ; elle est decorée de deux grosses rosaces corlées a $2 x$ lores, siparese par une ligne transversale de 6 pelites rosaces a l pélales. The rhaque rote du manche: en haul, une de ces petites rosaces, et en bas. un groupe de 4. dispose en losange. Ja hase est longee, du còté de la panse, par une ligne de petits traits obliques, legiement marqués eflarés en face des

5 TAL 7 ; ce sigle designe le produit des fouilles acturlles, faites sur un lerrain appele Tanrin, pres du

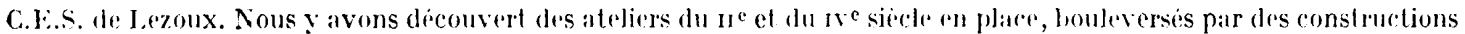
du lloyen Age. Lne pelile occupation du J $^{\mathrm{er}}$ siec Ie n'a laisse que quelyues lessons. 


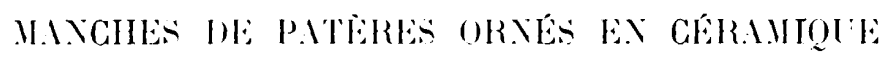

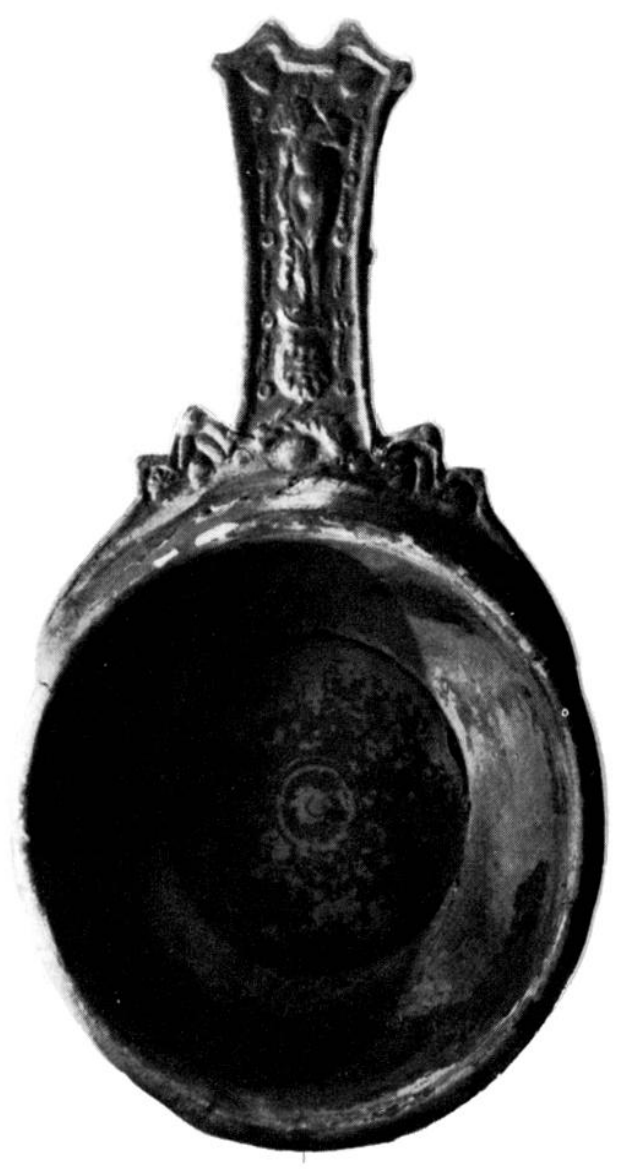

a 9

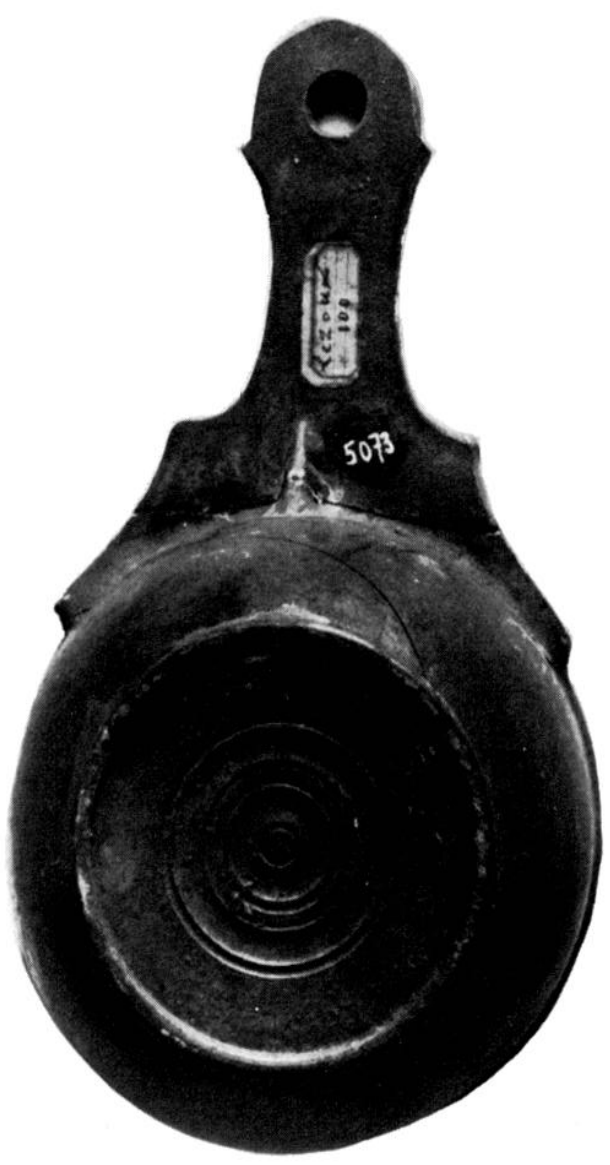

C 13

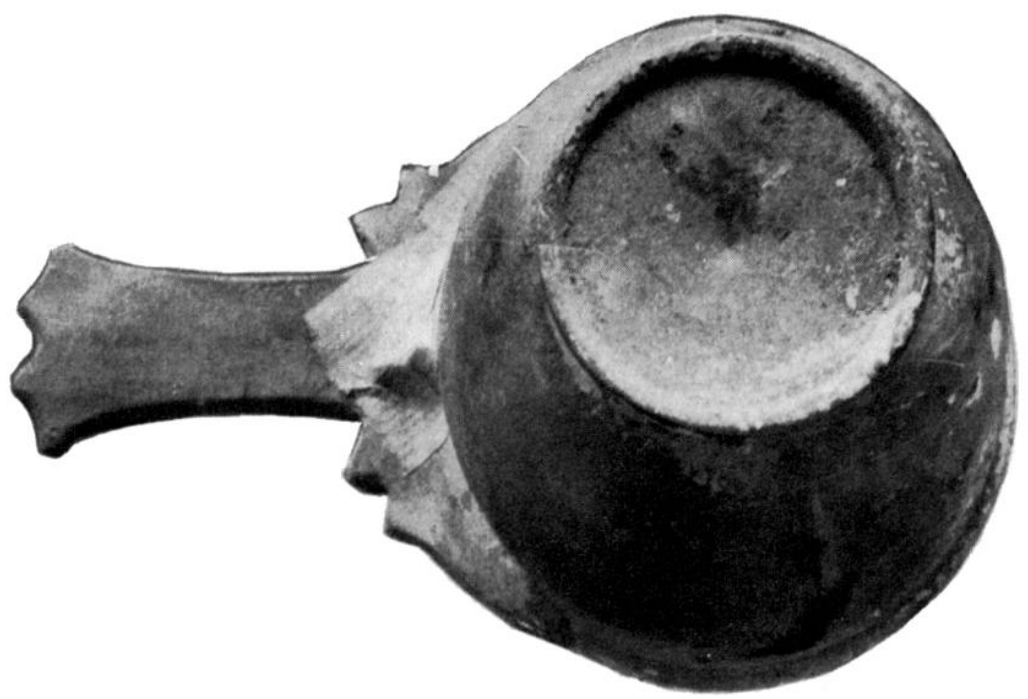

b 9

I'l. 1, ... Pateres du Muse de Clermont-Ferrand. a et b, manche no 9; c, no li3. Ce dernirer a un fond qui rappelle mettement les documents motallidues ; on distingur bien longlet qui supporte le collage du manche. 

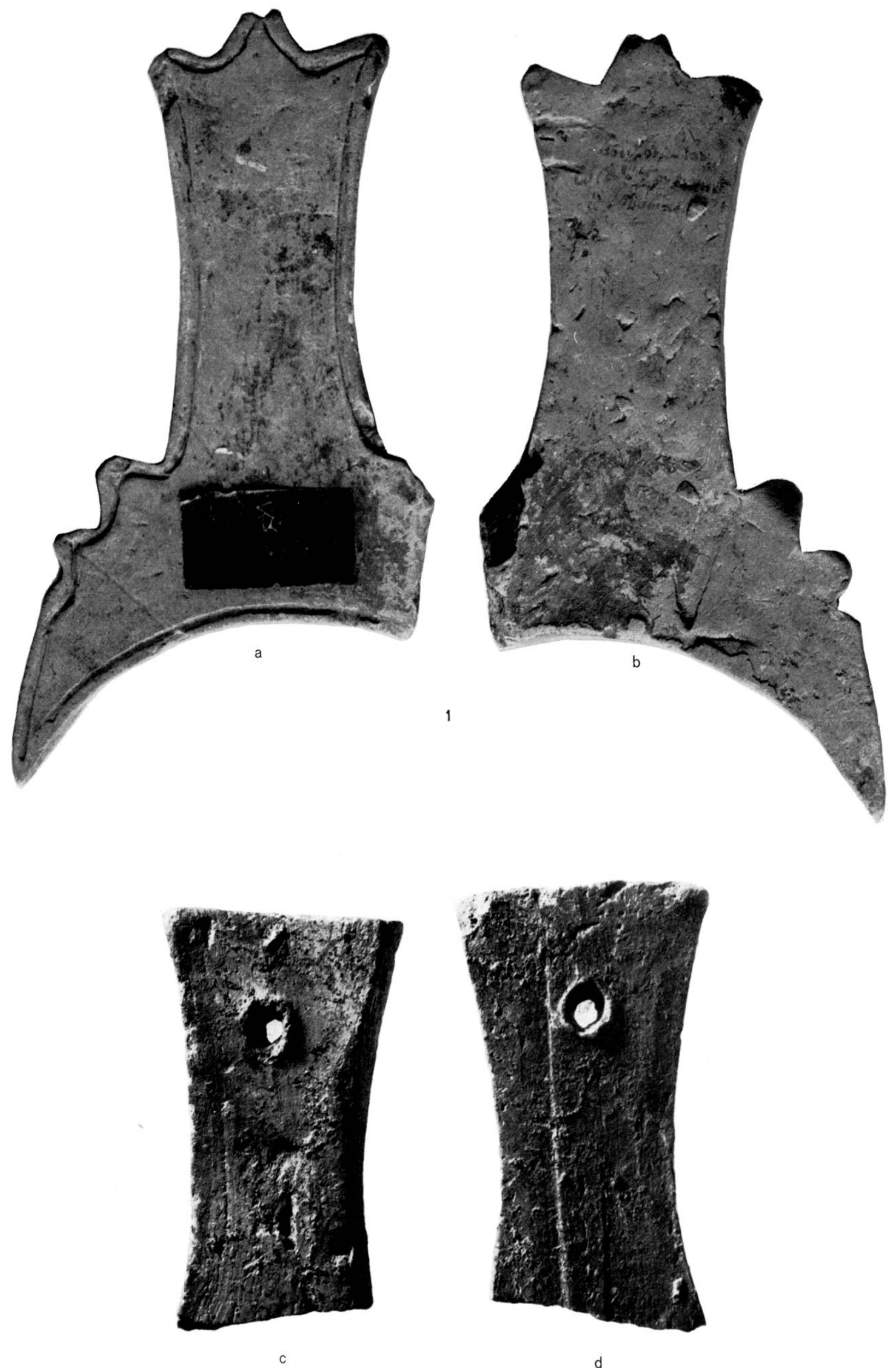

Pl. 2. - Malrices pour moules, en argile, massives. a, b : manche no 1 , la face d'impression id est lissee et porte une

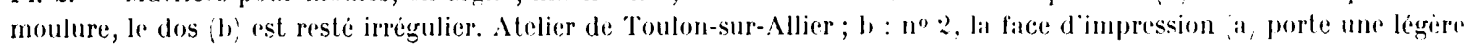
moulure, le dos ic; est irrégulier ; le trou de suspension ast fen soigne. 
têtes d'oiseaux, dont il ne subsiste que le début, de l'cil, à peine en relief. Deux rosaces à 12 pétales décorent l'épaulement.

Ornements n ${ }^{\circ S} 45,51,55,66$.

4. - Ateliers de Vichy, vraisemblablement, ateliers de la gare ${ }^{6}$. Musie de Moulins. Pl. 3 c. d. "Vichy" i l'encre.

Fragment de moule ; il manque l'extrémité et la branche droite : long. de la tige : $68 \mathrm{~mm}$. de la base : $104 \mathrm{~mm}$.

Argile rose; lissage au dos.

Line double moulure suit la tige, décorée de 2 grosses rosaces torsadées a 28 tores ; entre celles-ci. une feuille de vignne entourée de 4 petites rosaces ì 4 pétales. Lin ensemble de 4 aul res mèmes rosaces. en losange, est placé sous l'épaulement qui est timbré d'une rosace à 12 pét ales. Less branches portent des têtes d'oiseaux à cril allongé et très effacé : traces peu visibles de plumes dessinées en demirercle.

Mème double moulure, mème rosaces que sur le $\mathrm{n}^{0}:$; t tous deux sont vraisemblablement du même alelier et du même potier.

Ornements $\mathrm{n}^{\mathrm{os}} 24,45,51,5 \%, 56$.

5. -.- - Ateliers du Centre de la Ciaule (Vichy, Toulon?). Musée de Moulins. Pl. 4 a, b, c.

Moule; il manque seulement la branche droite; long. de la partie centrale : ext. $8: 3$ mm, int. $69 \mathrm{~mm}$; larg. du manche : ext. $42 \mathrm{~mm}$, int. 99 mm : épaiss. du moule : $15-17 \mathrm{~mm}$; profondeur du creux : : $5-7 \mathrm{~mm}$.

Argile blanchàtre. Le dos a élé lissé, puis quadrillé de lignnes obliques croisées. La décoration n'a pas été obtenue avec des poinçons-matrices, mais par l'impression d'un manche de patère déjà orné ${ }^{7}$ (en argile et non en métal, vraisemblablement).

L'anneau terminal est orné de 3 moulures plates concentriques. La place du trou de suspension est marquée. La tige est bordée d'une moulure plate qui enloure ausisi l'anneau, el de 4 autres moulures longitudinales qui se terminent sur la base par une petite échelle transversale de 7 barreaux, une ligne concave et deux traits croisés. La base porte, de part et d'autre, deux protomés d'oiseaux (?), avec un collier hachuré de 6 trails, les plumes de la lite étant, rendues par de petits arcs, celles du cou par des ares plus grands. L'épaulement est marqué d'un trou rond. Un défaut de moule abîme l'extrémité du bec de l'oiseau.

6. - Meliers de Lezoux. Collection Fabre-Ollier, La Gagaire, Bort l'Élang (Puy-de-Dòme). Pl. 4 c. d.

Houle ; il manque toute la partie grauche. Long. de la tigre, de la base à l'extrémite : $87 \mathrm{~mm}$; larg. de la demi-base : (6i) $\mathrm{mm}$; épaiss. tolale du moule : $4-7 \mathrm{~mm}$, de la paroi du fond : $18 \mathrm{~mm}$; profondeur du creux : $5-7 \mathrm{~mm}$.

Terre rose, traces de lissage au dos, dont il manque de grandes écailles.

Une double moulure suil la tige et l'extrémité, décorée d'une grande coquille aux nervures guillochées el de deux petites rosetles. La tige et la base sont ornées de 3 esperes de rosettes de grandeur diflérente, d'une palmelte stylisée et de petits rouleaux. Lees branches portent des têtes d'oiseaux aux yeux ronds : les épaulements, des coquilles.

Ornements nos $1,2,42,53,66$ : rosace et palmette non réperloriées.

7. -. Ateliers du Centre de la Ciaule (Vichy?) ; legs. A. Kambert, .I.A..., no 49717 (éliquette ancienne 724 . Pl. 5) a, b.

Ioule ; il manque les deux branches ; long.. prise au centre ext. : $99 \mathrm{~mm}$. int. : $89 \mathrm{~mm}$; épaiss. du moule : $17 \mathrm{~mm}$; profondeur du creux : $5 \mathrm{smm}$.

6 Cies aleliers ont ite decouverts lors de la construetion de la gare sivile et fouillés en partie par Bertrand.

7 V. plus loin " Fabrication". 


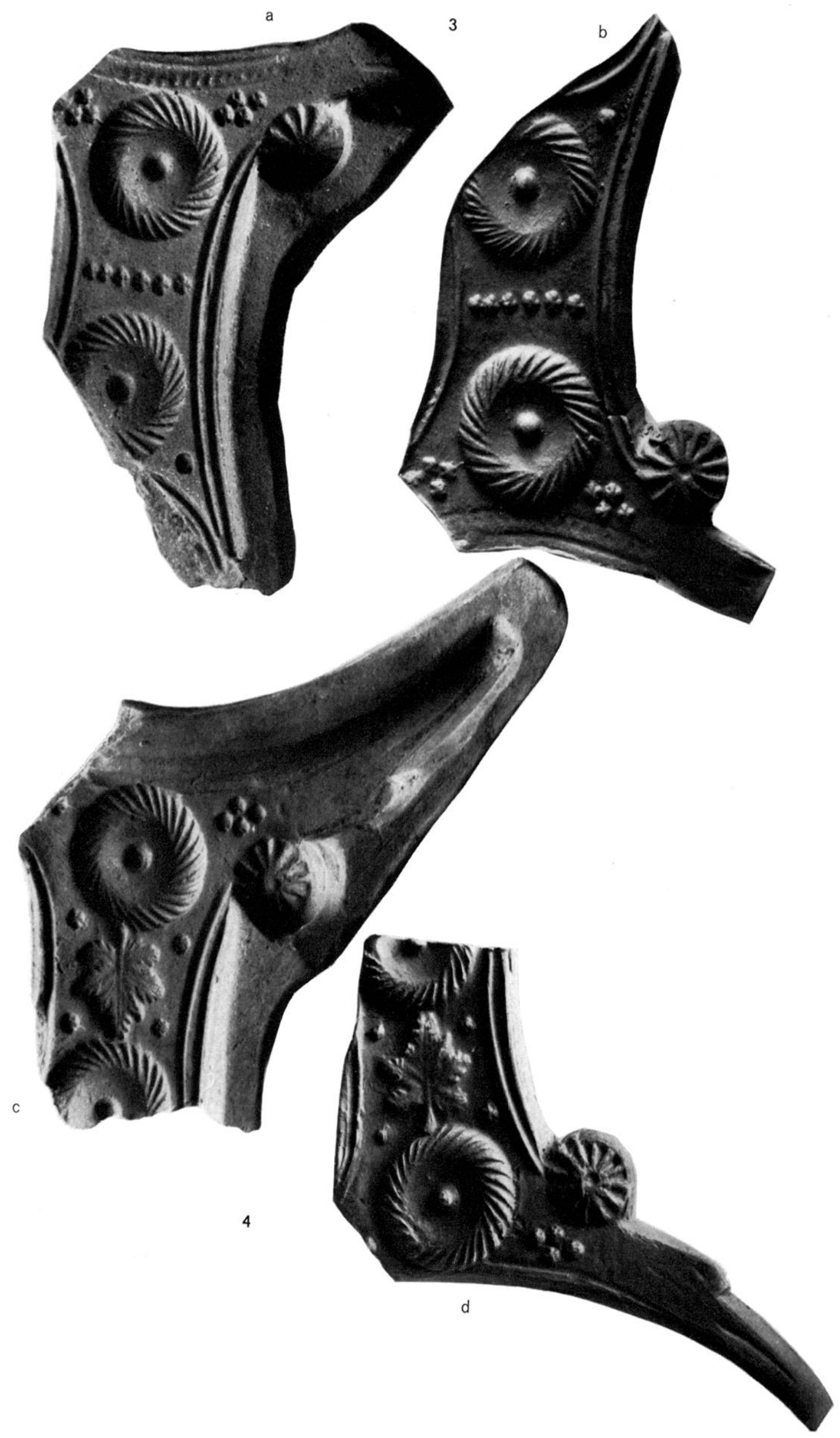

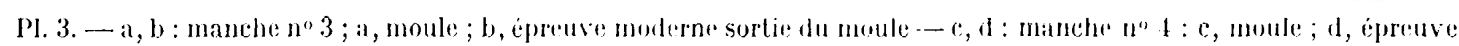
moderne sortie du moule. Les deux moules sont sortis des mains du mêmr potier. Mteliers de Vichy probablement. 


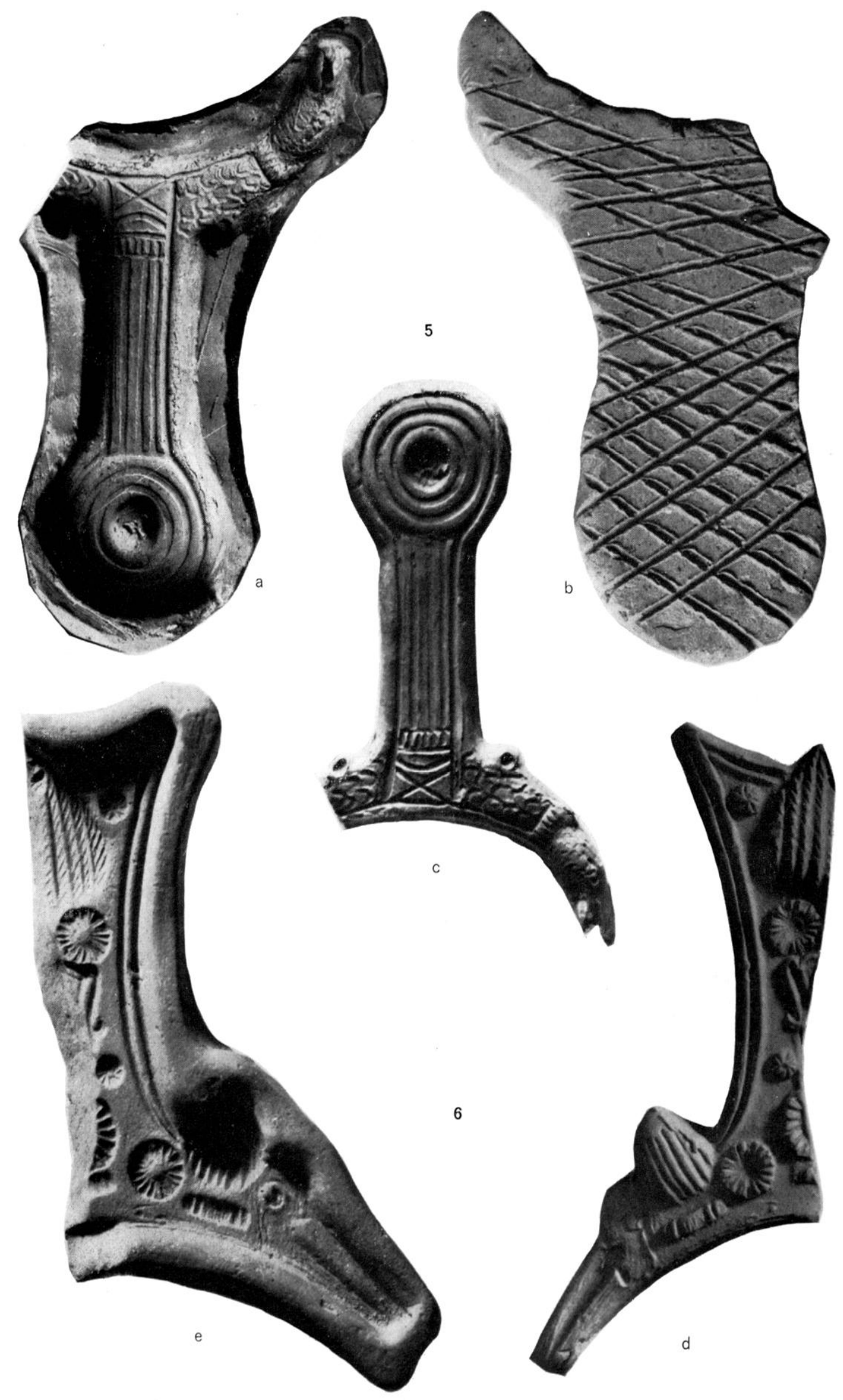

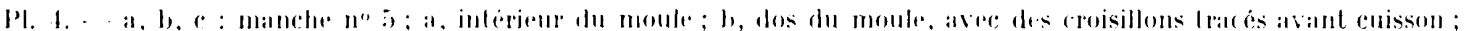

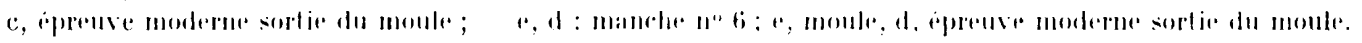




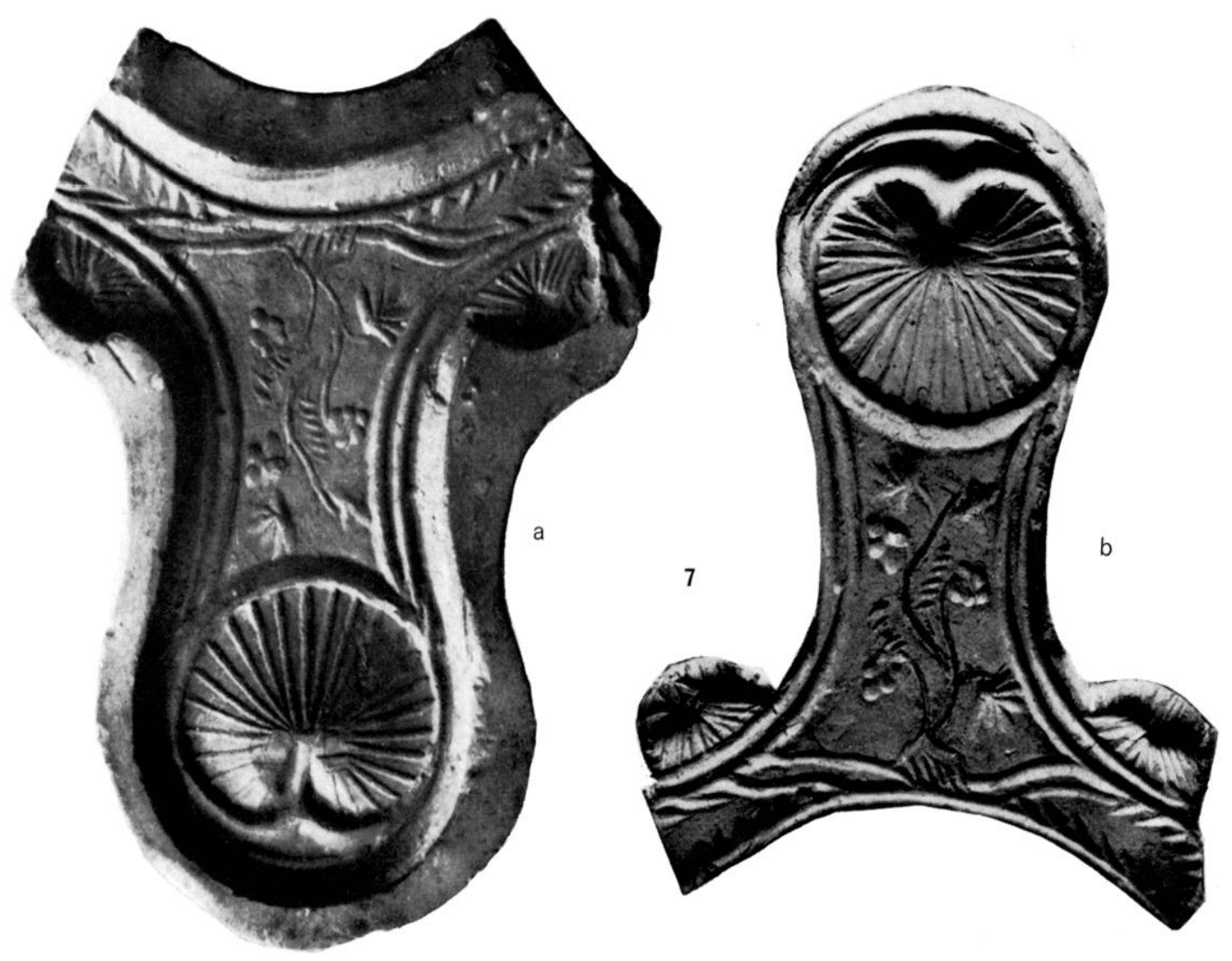

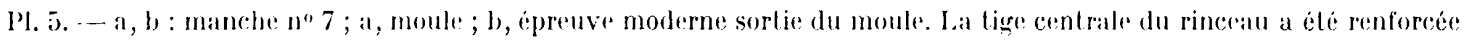
avec un trait de crayon sur l'original.

Terre rose ; surface du dos. chamois ; dos relaillé.

L'anneau lerminal est oreupé par une large roquille, entourée d'une simple moulure; une double moulure longe la tige el descend vers les branches. Le centre est occupe par deux petits rameaux portant trois erappes, deux vrilles, trois feuilles; ils se rallachent a deux sarments qui longent la base. Celle-ci est marquée, du rote de la panse, par des petils traits obliques dont l'inclinaison est inversée de chaque cote de l'axe du manche el qui suivent les deux cotés des branches. les épaulements sont timbrés de coquilles. Feuillages et traits obliques ont été gravés en creux, a la gouge, sur le prolotype.

Ornements nos 70,76 , el décor gravé.

8. - Ateliers de Lezoux. M..A.X., no 32464 ; J.I.. p. 317, no 12 et pl. VII ; no 1. PI. 6 a. b.

Noule : il manque la plus grande partie de l'anneau terminal ; larg. entre les branches : ext. $12: 3 \mathrm{~mm}$, int. $119 \mathrm{~mm}$; épaiss. Lotale : 2:3 a $28 \mathrm{~mm}$.

Terre rose; intérieur de la paroi : noir anthracite ; surface du dos : jaune.

L'anneau terminal est entoure d'un erinelis, la lige, orné d'un trapeze curviligne a triple moulure, très régulier. Au centre, sortant d'une loufle de trois leuilles, s'élive une plante, portant trois fleuretles a :3 pélales, el deux pelites feuilles a mi-hauteur. Ni les branches, ni les épaulements ne portent de décor.

Ornements nos $33,56,68$.

9. - Ateliers du Centre de la Gaule. Musée de Clermont-Ferrand, sans origine (Lezoux?), no 54.1.171. Pl. 1 a, b (dessus et dessous) ; manche, pl. 7 a ; profil, fig. 2 a. 


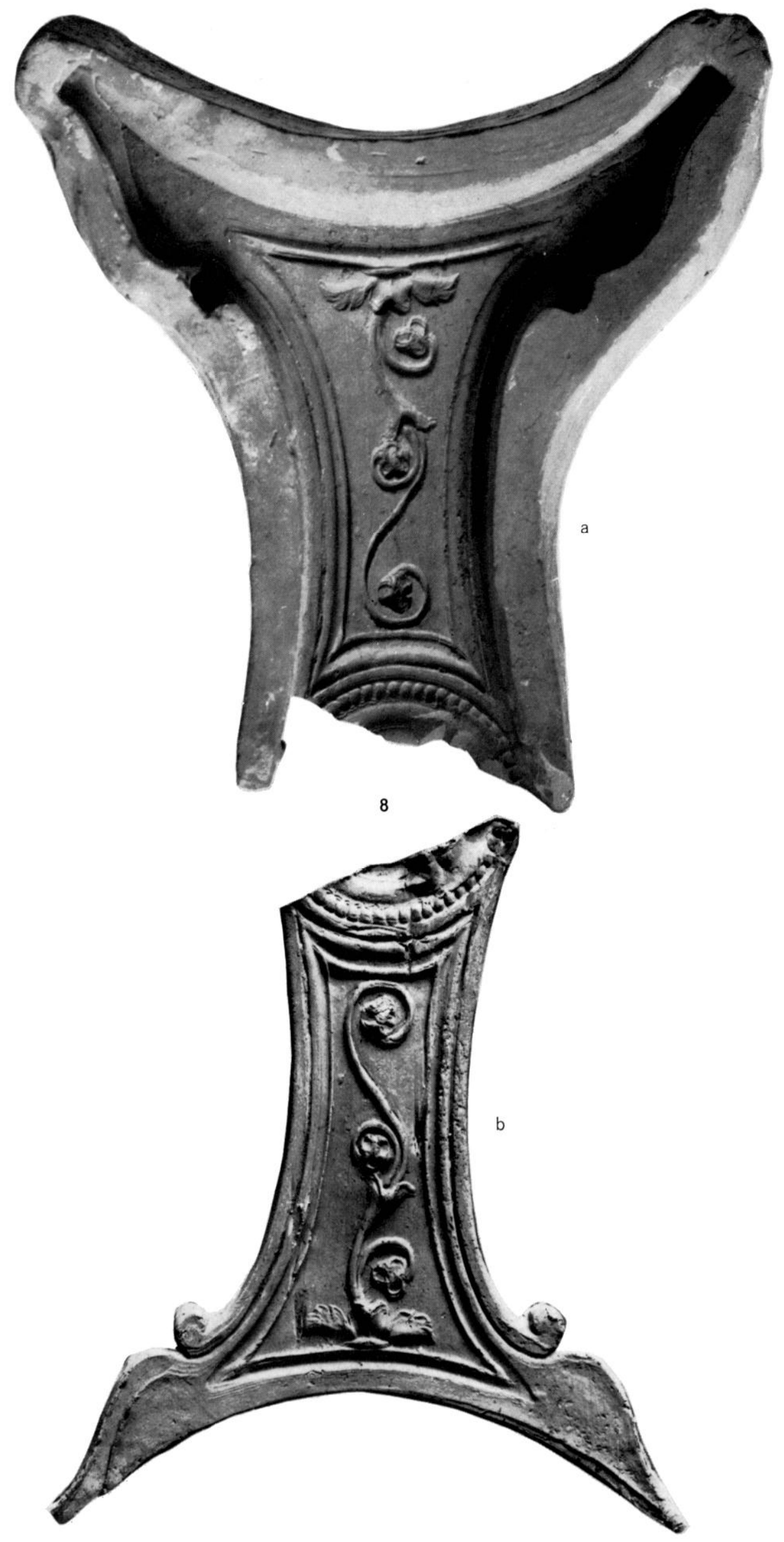

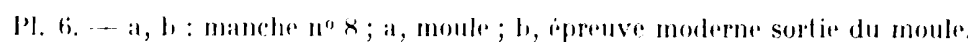



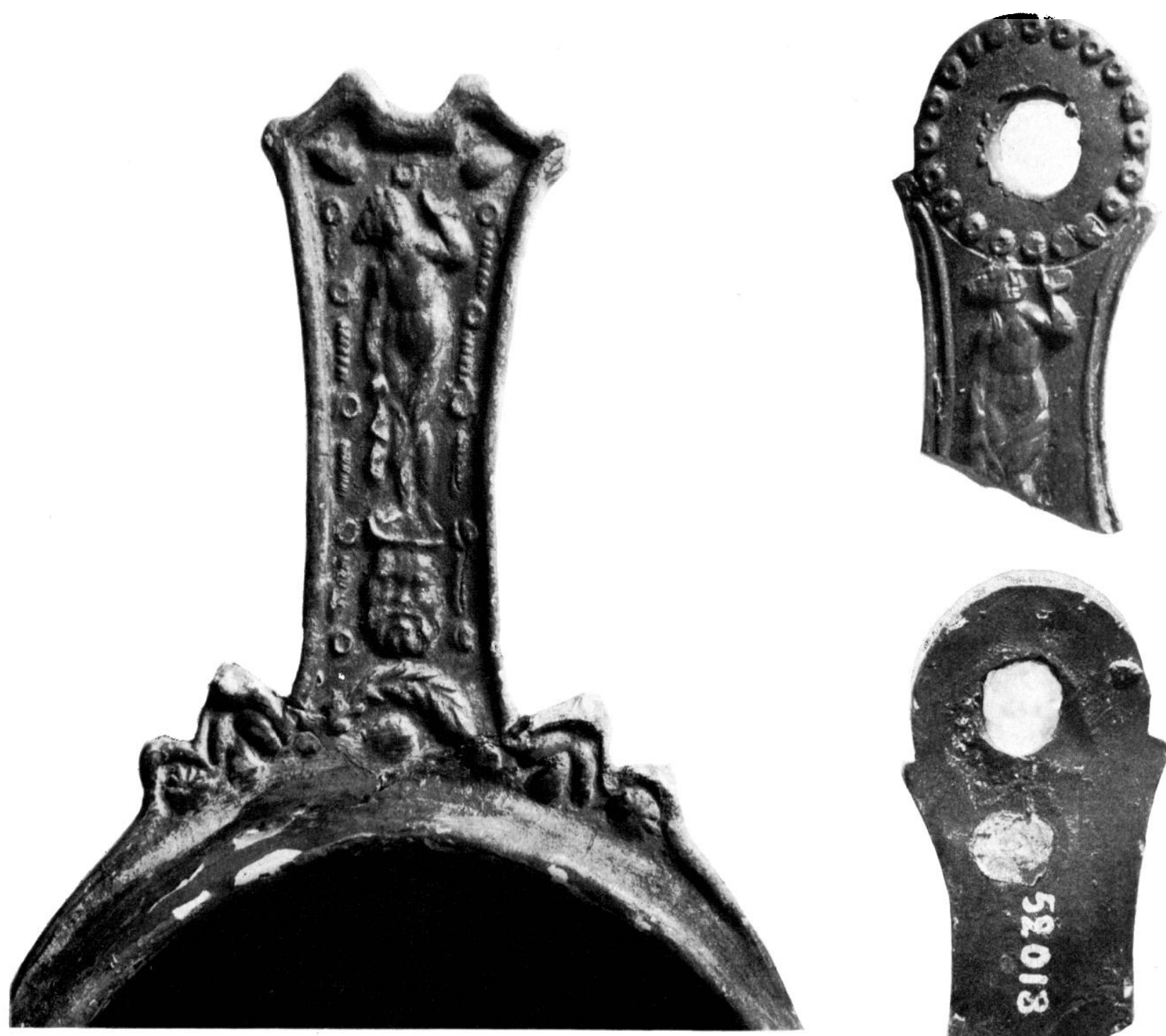

b 10

a 9

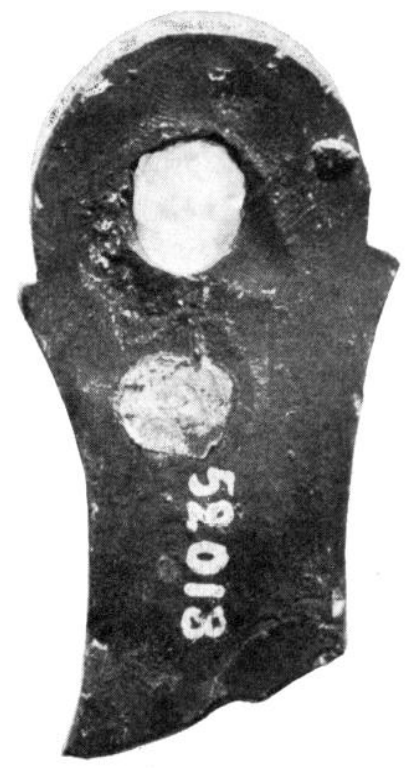

c 10
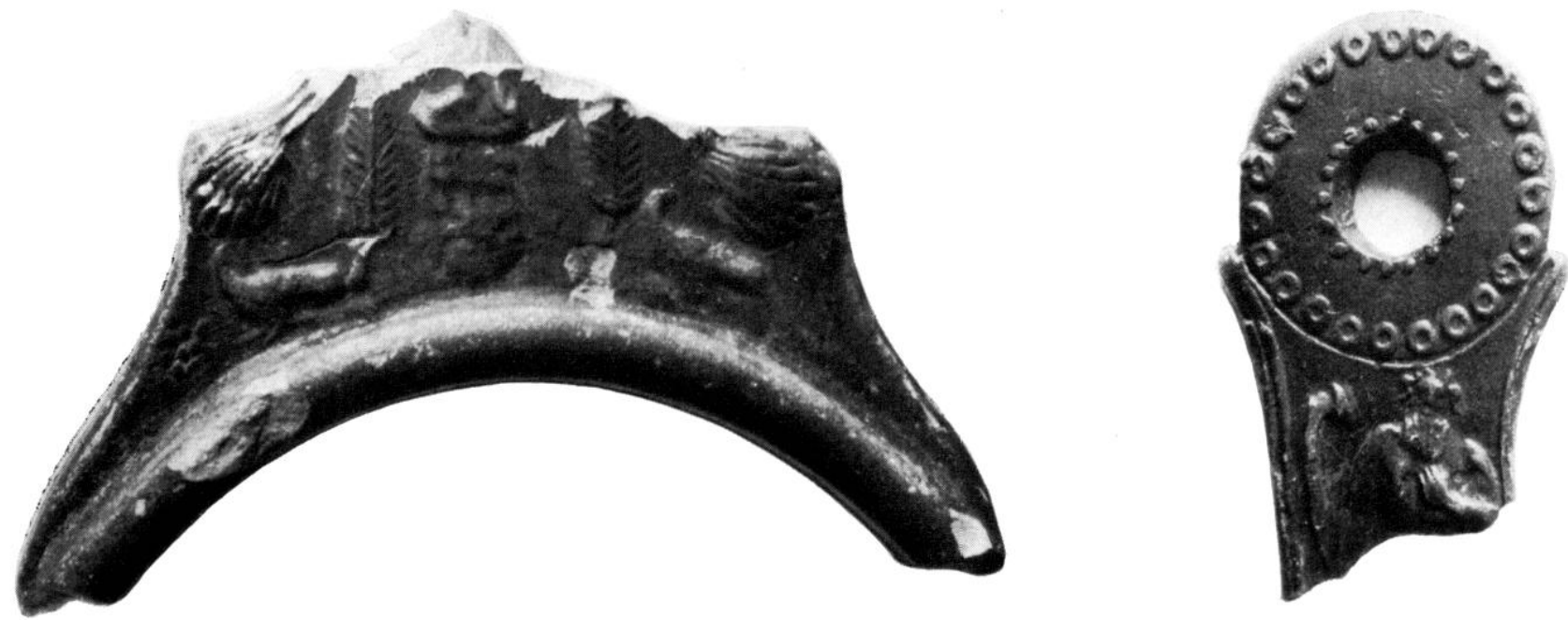

d 12

e 14

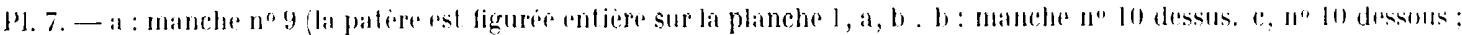
on roit la frace blanche de larrachement d'un support de cuisson. d : manche n" 1 : ; 1 : : n" 14. 


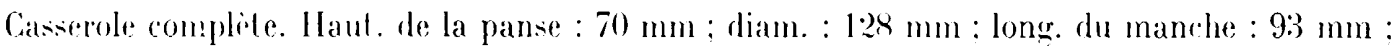
epaiss. du manche : 6-7 mm.

Argile beige clair : engobe rougeatre peu solide, subsiste par plaques.

Le manche est entouré d'une moulure assez haute. L'extrémité porte deux petits ornements trrappes?. La lige est ornée d'une Vénus nue. debout de face ; de sa main droile elle retient une draperie yui descend de ses hanches et entoure ses genoux : sa main droite tenait un miroir, ou se regardait la déesere mais cet atcessoire n'existe plus ici. Sous ses pieds, un socle plat. mince relevé

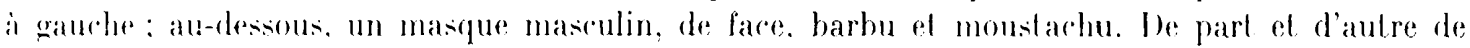
rel casemble. une ligne de vrilles allerneses aver de pelits cercles. Sous le masque, une palme, dans l'arrondi de lacquelle est une rosice. I.es branches ne sont pas decorées. I'n double épaulement presente une rosace et trois petits ornements ovoüdes igrappes?.

Ornements $n^{\text {os }} 1,31,44,54,62,64$.

9) bis. -.- Le Musé de Clermont conserve une deuxiome casserole identicque au no 9.

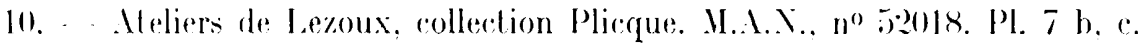

liagment de manche : il manque la base el une partie de la tige: long. : 70 $\mathrm{mm}$; diam. de

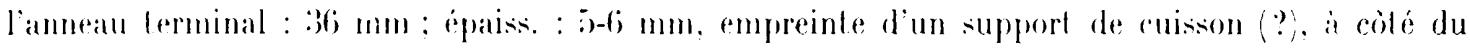
tron de sili-pension.

Terre rose : surfare : vernis rouge de la sigillée.

lianneau terminal est entoure de petits cercles el son pourlour est cerné d'une petite goroge, vers le has. Le trou de suspension a été percé au milieu d'un cercle de grichetis. qui a eté en grande partie eflacé par cette opération. La tige est longée de chaque coló par une double moulure. Au centre. variante de la Vénus du no 9, assez bien venue.

Ornemenls $n^{\text {os }} 1^{\prime}$, i.t. (66., 69.

11. Meliers de Lezoux. collection Plique, M..... Pl. 8 d.

Hanche de patire: il mancque une grande partie de lanneau terminal et le bec droit; long. prise all centre : $71 \mathrm{~mm}$ : larg. aux épaulements : $68 \mathrm{~mm}$; épaiss. : 12 mm ; épaiss. de la panse : i) $1 \mathrm{~mm}$.

Paite rose : surface noire, vernis luisanl, absent sur tes reliefis.

L'anneau terminal est entouré d'un grinetis et son pourtour est souligné d'une petite gorge. vers le bats. la lige est longée. de chaque coté, par une moulure simple, puis par une ligne de petils rercles. Iu centre. debout sur un masque, la mìme Vénus que sur le 10. Le masque, presque eflacé par le collage sur lo rebord de la panse, esl encadré par deux colombes, qui sont tournées vers la gauche et regardent en arricre puis par deux rosaces a dix pétales. Les branches ne sont pas ornées; les épaulements sont limbrés de rosaces à 7 pétales.

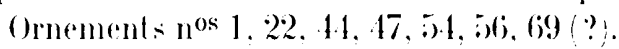

12. - Meliers de Lezoux, collection Plicque. M.A.X., no 52018. Pl. $7 \mathrm{~d}$.

Mamrle de paliere: il ne subsiste que la base el te début de la lige onglet an-dessous ; plus wrande dimenson : $10.4 \mathrm{~mm}$ : larer. entre les couquilles : $69 \mathrm{~mm}$; épaiss. : 9) a $10 \mathrm{~mm}$; épaiss. de la panse : 3) $\mathrm{mm}$.

Terre grise: surfare noir anthracite; plus claire sur le dessus.

la lige. longée par une double moulure était ornée de la mème lónus que les nos 9, 10, 11. l.e matique. asser mal venu. est enradre de deux palmes rectilignes, plarres verticalement et de deux rolombes variantes de celles du $\mathrm{n}^{0} 11$. Au départ. de la branche crauche. une grappe de raisin ; reelle de droite n’a pas élé imprimée. les épaulements sont timbrés de cocquilles.

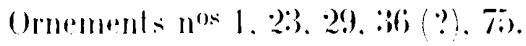

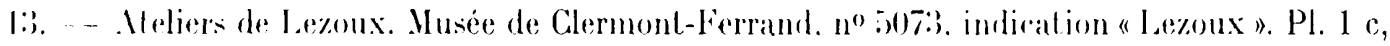
fond : profil. fig. 2 b : manche, pl. 8 a. 


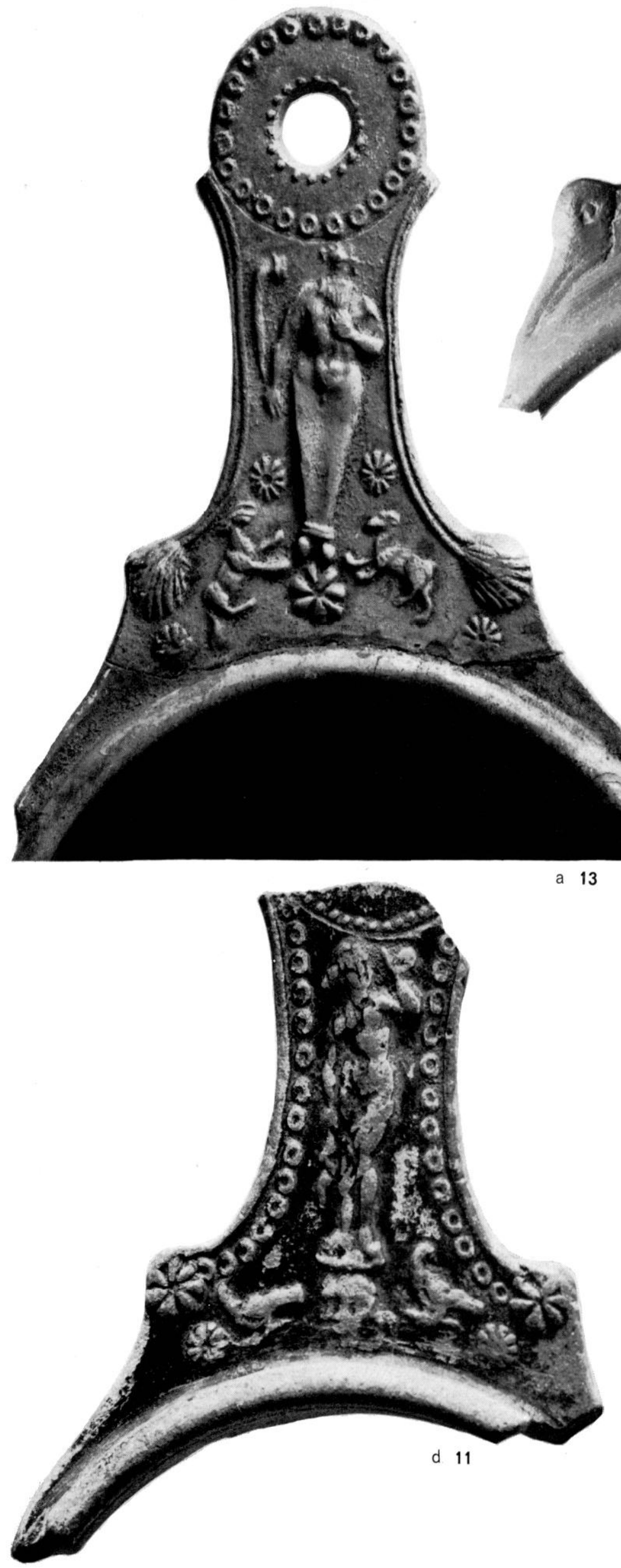

b 17
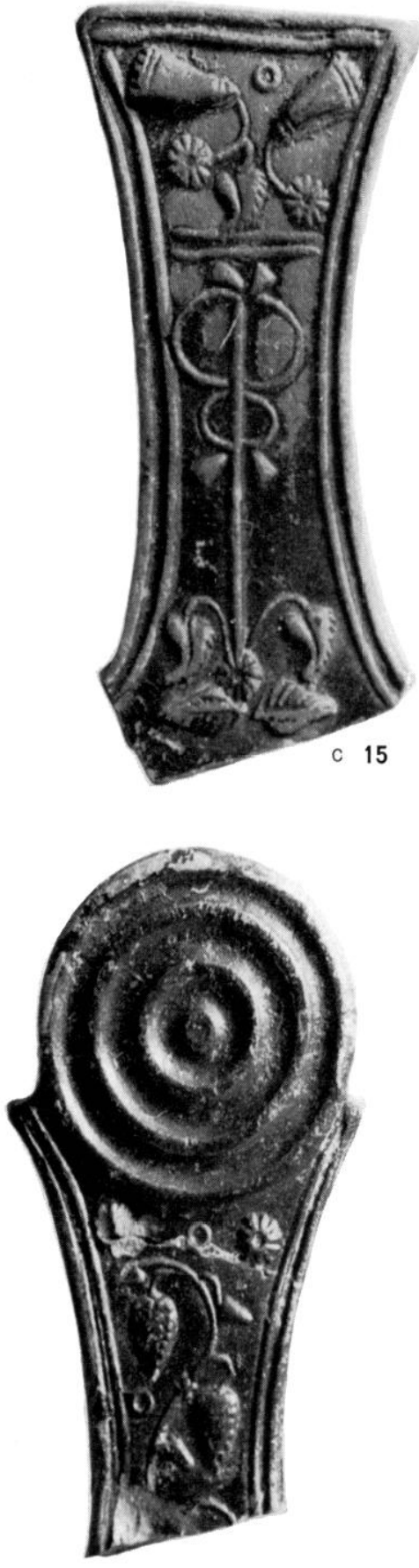

e 16

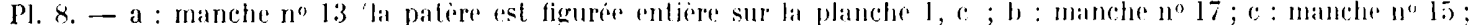
d: manche n" 11 ; e: manche $\mathrm{n}^{\circ} 16$. 
Casserole compliete: haul. de la panse : $72 \mathrm{~mm}$; diam. : $123 \mathrm{~mm}$ : long. du manche : 95 mm, épaiss. : $5-7 \mathrm{~mm}$. Son excellent état de conservation laise supposer qu'elle a peut-ìtre été trouvée, comme le no 9. dans une lombe, a Lezoux.

Aroile urise : surface gris anthrarite, intérieur et extérieur.

L'anneau terminal est contouré d'une ligne de petits cercles et son pourtour est souligné d'une petile gorge vers le has. Le lrou de suspension a éte peré au milieu d'un cercle de grinetis. Ia lige est longée de chaque colé par une double moulure. Au centre, un Ifermés de Pan. Ine sa main droite. il tient le pedum, qui a la forme d'une lrompelte : de l'autre main. il porte la syrinx a ses lives. Ia tôte est asse\% mal venue, mais la musculature du lorse est assez bien mouléte sous ses pieds. une rosace a 7 pétales : de part et d'aulre, une rhive el un bélier: devant et derriore ces animaux, une petile rosare a 10 pétales. Les branches ne sont pas décorées : les epaulements portent des roquilles.

Ornements $\left.\mathrm{n}^{\mathrm{os}}: 3,20,21,44.47,54,66,69\right)(?$.

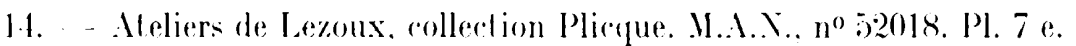

Manche de patere, il ne subsiste que l'anneau lerminal el une part ie de la lige ; long. : $59 \mathrm{~mm}$; diam. de l'anneau terminal : 36 mm ; épaiss. : : a 7 mm.

Aroile rose : vernis rouge de la sigillée.

L'anneau terminal ef le haut de l'Hermes de Pan sont en tous points identiquess a l'exemplaire 14 ; vraisemblablement. les deux documents sont sortis du mème moule.

Ornements $n^{\text {os }}: 3,14,54,66,69$.

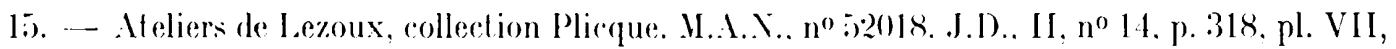
n'11. Pl. 8 c.

Manche de patire; la base manque ; long. : $84 \mathrm{~mm}$; larg. de l'extrémite : 42,5 $\mathrm{mm}$.

Argile rose, surface noire, sauf sur les reliefs, ou l'enduit est mince el, ou la couleur rose reapparaîl.

L'ensemble est entouré d'une double moulure; l'extrémiti. rectiligne, est délimitée par deux moulures transiersales et décorée d'un petit rercle el de deux liges terminées par des rosaces; celle de droile porte une feuille arquée. Ces tiges sortent d'objets triangulaires portant, a la base, des franges. Le fait que la lige est ornee d'un altribut de Jercure fait penser ici a des bourses.

Ia lige porte un caducee, auquel sont atlaches des ornements triangulaires en forme de clochettes peut-idre a rapprocher des vrilles du no 16 . Sa base repose sur une rosace a 10 pébales d'ou partent deux pétioles de deux feuilles argués. Au-dessous, deux pelites feuilles rectilignes opposées.

Ornements nos $26,27,: 38:, 40,43,54,66$.

16. Meliers de Lezoux, collection Plicque. M.A.X., no 5201s. Pl. 8 e.

Manche de patira : il manque la base et le bas de la lige. Iong. : 81 mm : epaiss. : $7-8$ mm.

Aruile gris-rose ; surface noire.

I.'anneau terminal a ete imprime dans le moule aver une matrice fournée comme le montre la récularile des cercles concentriques. Ia lige est longée de rhaque cote par une double moulure. Ein haul, deux roselles a 10 pritales ef un petit cercle. An centre. un sarment de vigne, lerminé par une petite feuille. Ies grappes de raisin et des vrilles y sont rathacheses de chaque coté.

Ornemenls $n^{0}: 37,38,4: 3,45,34,66$.

17. - Aleliers de I.ezoux. collection Plicque. M.A.... no i2018. Pl. 8 b.

Manche de patire: il manque lextrémite ef le haut du manche. Plus grande dimension du lesson : $92 \mathrm{~mm}$; largeur d'une coquille a l'autre : 5.) mm. le pourtour a dé retaile. ce qui a eflace en parlie les roquilles des epaulements.

Argile rose ; vernis rouge de la lerre sigillée.

La lige est longee par une seule moulure; au centre. un sarment de vigne, aver une grappe et 

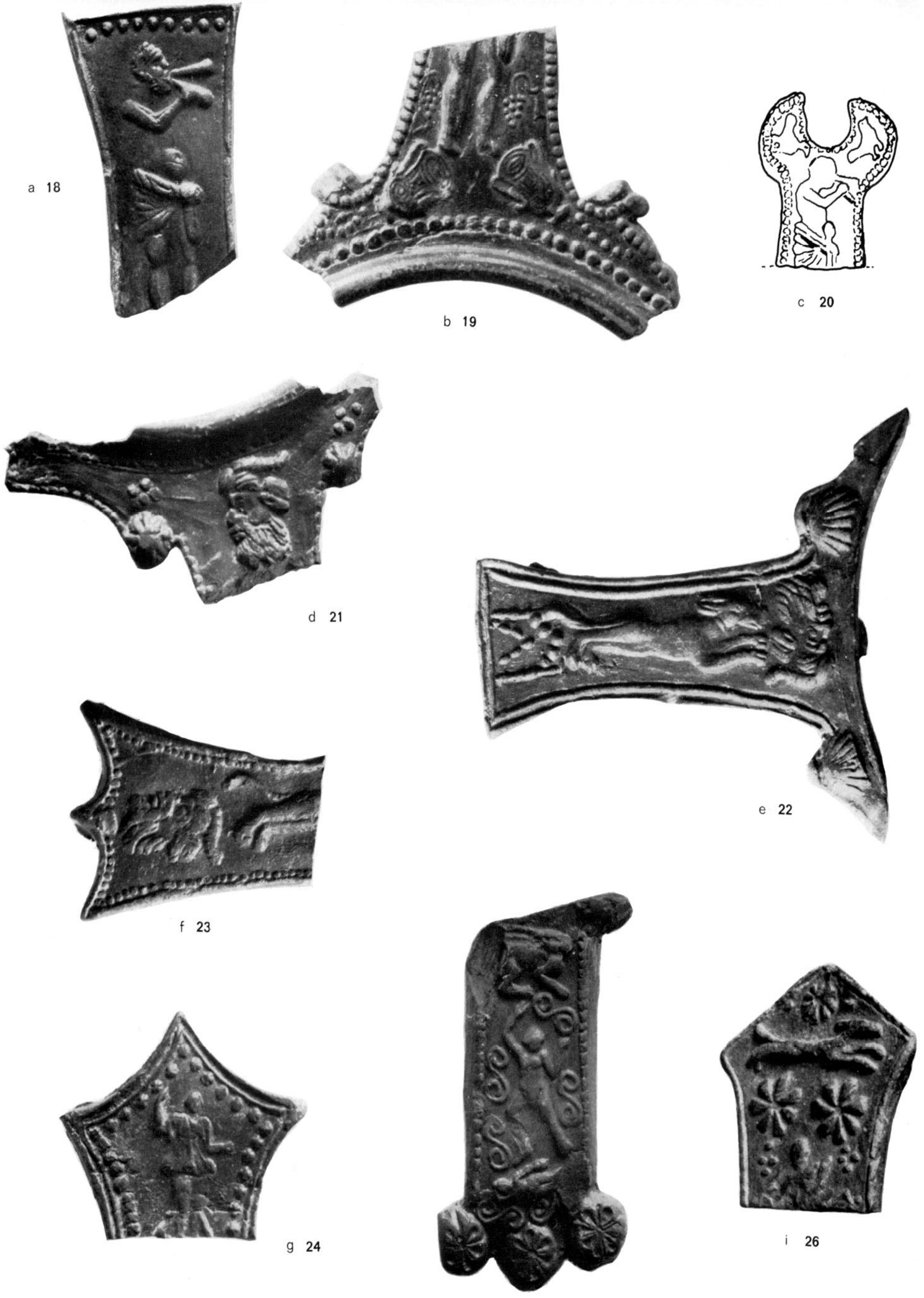

i 26

h 25

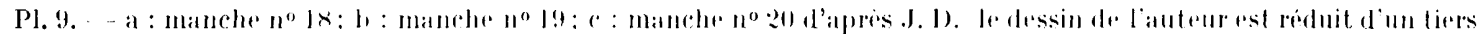

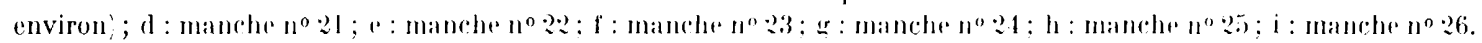


deux feuilles. sur la base. deux petites rosaces a 10 pélales et deux pelits rouleaux placés verticalement. Les branches sont ornées de tìtes d'oiseaux à l'oil rond ; les doubles épaulements, de cuvette et de coquille.

Ornements nos 25,37 (?: 41, (3.). 77, 78.

18. Ateliers de Lezoux, collection Plicque. V...... no 52018. Pl. 9 a.

Manche de patere ; il manque la hase et le bas de la tige. Long. : $58 \mathrm{~mm}$; larg. de l'extrémité : $18 \mathrm{~mm}$; épaiss. : $6-7 \mathrm{~mm}$.

Arcrile rose : vernis rouge de la terre sigillée.

L'ensemble est entouré d'une moulure simple : a l'extrémitr. rectiligne, un grrènetis. Au centre de la lige, un siline demi-nu, tourné vers la droite el jouant de la double flùte.

Ornements nos 8,68 .

19. - Meliers du Centre de la Ciaule (Vichy?: legs A. Rambert. M.A.X., no 496 84. Pl. 9 b.

Manche de patire: il manque le bout des deux branches, le haut de la lige et l'extrémilé; plus grande dimension : $80 \mathrm{~mm}$ : d'un épaulement a l'autre : $58 \mathrm{~mm}$; épaiss. de la panse : $5 \mathrm{~mm}$; onglet.

Arovile gris-rose : surfare noire sur les reliefs, luisante comme mélallisée dessous. Sur les reliefs, le vernis, clair, laisse voir la pàte.

La lige est longée par un grinetis. Au centre, le mème silene que sur le no 18 ; de part et d'autre de ses jambes, une zrappe aver pédoncule; sous ses pieds. deux crateres obliques. Ies branches, comme les épaulements, sont décorées de grinetis.

Ornements nos $8.36,60.67 .68$.

20. - Ateliers de Lezoux, collection Plicque. V.A.X., non retrouvé encore; J.I)., II. p. 317, no 10, et pl. VII, no (i. Pl. 9) (.

Manche de patire ; il manque la base et une partie de la tige.

Arovile rose : vernis rouge de terre sigillée (d'aprés J.I). II, p. 317, no 8).

l'anneau terminal a été ouvert volontairement, jusqu'au trou de suspension, re qui donne. a l'extrémité du manrhe la forme d'un croissant. Cn grènetis en suit les contours et descend le long de la tige. Jans chaque branche du croissant. un oiseau tourné vers la droite. Sur la tige, le mème silene que sur les nos 18 et 19.

Ornements $\mathrm{n}^{\mathrm{os}} 8,69$, oiseau non figuré.

21. - Meliers de Lezoux, rollection Plicque. M.X.X.. no 52018. Pl. 9 d.

Manche de palere: il manque la branche sauche. la tige, et l'extrémité. Plus grande long. : $79 \mathrm{~mm}$; épaiss. : 4 -i) $\mathrm{mm}$.

Argile rose; vernis rouge de la lerre sigillée.

la tige était longée par un grienetis. Au centre de la base, un masque de Pan ; de part et d'autre. un losange de 4 points. Le bord de la panse est longe par un grinetis. Les épaulements sont timbres diune rosace lres proéminenle. i 9 pétales.

Ornements $n^{0 \%} 4.45 .50,69$.

2.2. - Meliers de Lezoux, collection Plicque. М.A.X.. no 52018. J.1)., p. 317 et pl. VII, 9. Pl. 10 e.

Manche complet : long. au centre: : $\$: 2 \mathrm{~mm}$ : larer. de l'extrémité : :35) nmm, au niveau des branches : $84 \mathrm{~mm}$ : onglet au-dessous, haut. : $6 \mathrm{~mm}$.

Irgile rose; vernis rouge de la terre sigillee.

l'ensemble est longé d'une double moulure. L'extrémité rectiligne porte un ornement curieux, forme de deux lignes de points de laille diflérente frollier?. La tigne est decorée d'un rhien courant 
vers la droile el d'une file de Pan. place a l'envers. Les branches sont lisses. Ine coquille limbre le premier cepaulement de rhaque cold : plus loin. une ebauche d'épaulement reste nue.

Ormements nos $;) .16,1 ; .7 .7$.

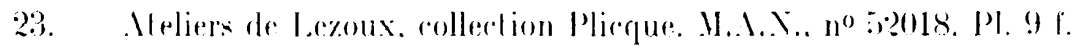

Vanche de patiere: il manque la bese el une partie do la lige : long. an rentre : $)$ ll mm : larg. entre les poinles: 42 mm : epaiss. : (i-7 mm.

Iroile rose : vernis rouge de la lerre sigillée.

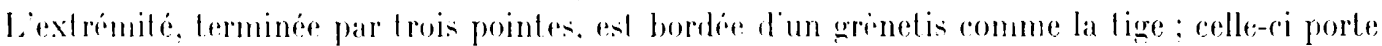
une tele de Pan. puis un animal lohien? courant vers la droite.

Grnement: $n^{0 s}(i, 17,69$.

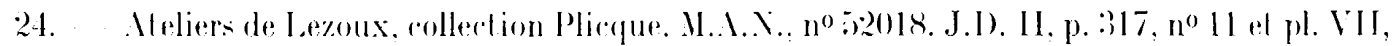
no 4. Pl. 9 电.

Manche de palire: seule subsiste l'extremite: long. au centre: 41 mm: lare. entre les deux poinles : $52 \mathrm{~m} \mathrm{~mm}$.

Argile rose, vernis de la terre sigillée.

Lextremile. Lermine par trois poinles est entourese comme la lige, d'une domble moulure, puis d une ligne de pelites rosares a 4 prilales. Au rent re. me Virtoire deboul.

Grmements nos 11. 4i). (ifi.

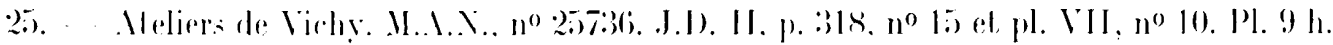

Manclee de palere. la base manque: longe : 70 mm. lige cpaisse rectangulaire irréguliere, 11 a 8 mmo. Pourlour retaille avant rolisom.

Araile rose. vernis rouge de la terre sigillée.

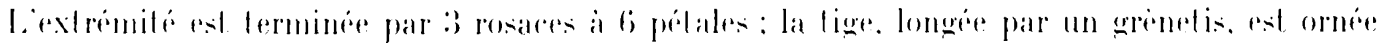
an rentere d'un personnage nu. les bras leves. Au-dessus de lui. un lapin. au-dessous une fenme mue. imprimé horizontalement. six ornements en sont disposes autour du personnage rentral. Lópantement ne semble pas decoré.

Ornements nos 7. 9. 19. 48. 61. 6is:?

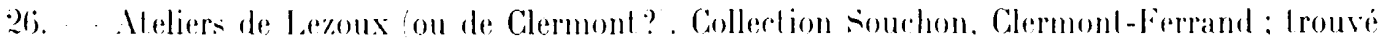
dalls celle ville. Pl. !) i.

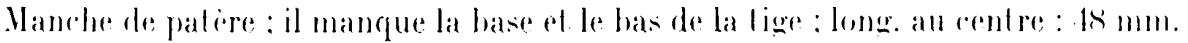

Areile rose : vernis rouge de la lere sigillée.

L'ensemble est entoure d'une moulure simple: l'exlremite. a i pointes. est orne d'une rosace de de deux points. Au-desous. un rhen rourant a droile. La lige presente Hereule. Au-desius de lui. deux rosares a 7 branches. A la hauleur de chaque epaule, 1 poinls en losange.

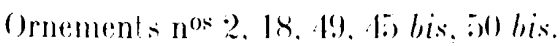

27. Meliers de Toulon-sur-Mllier. Collection liertrand. Musé de Moulins. d'apres J.I). :

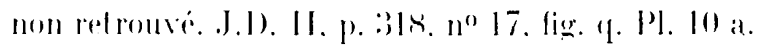

Manche de paliere: il manque la branche gauche el l'extremile de la droite.

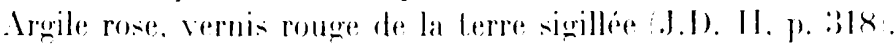

Linsemble est entonri diune moulure simple; lextremile porle 1 renflements arrondis: clle est décoré de deux leurons et de 3 points: le trou de suspension est entouré d'un grinelis.

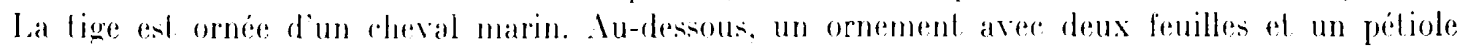
lerminé par un point. sur la base deux petils gladialeurs affronles. all-dessus de lestanpille rétro-

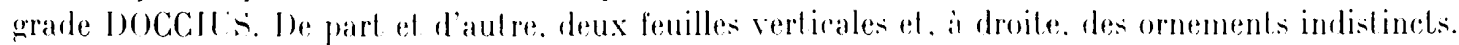
Il semble y avoir eu trois ćpaulemento non décorés.

oOCGILs est un polier que nos fouilles de Toulon-sur-. llier nous permellent de mieux connaî- 

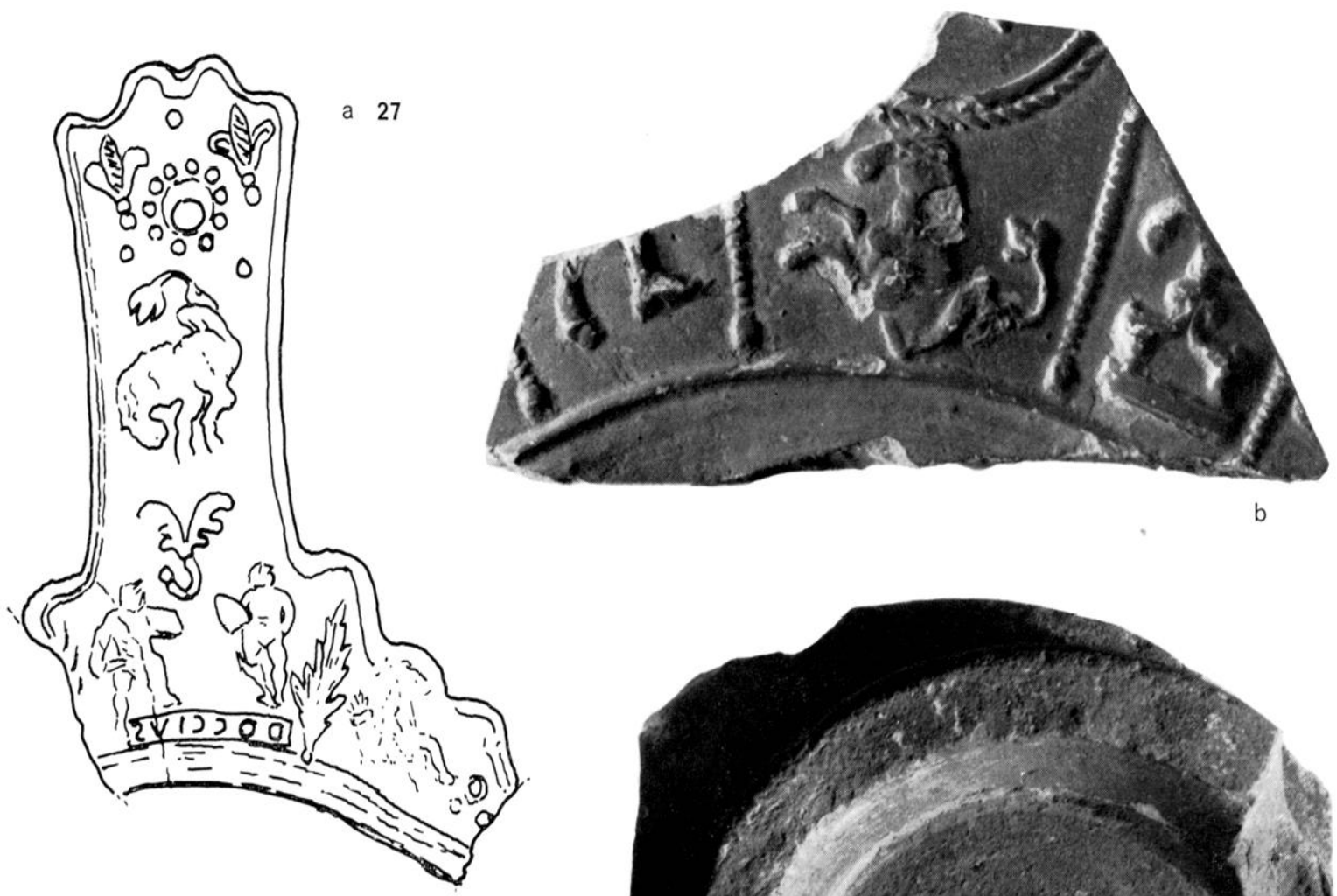

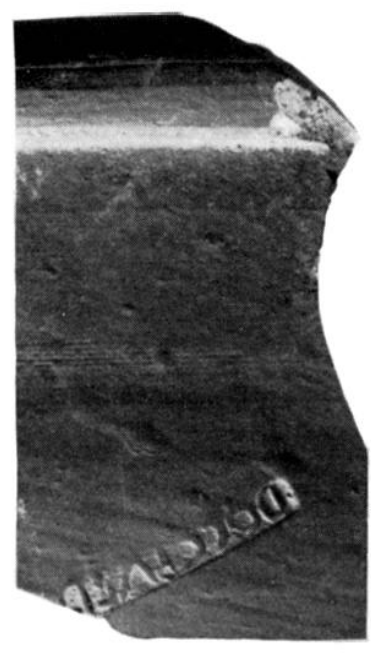

d

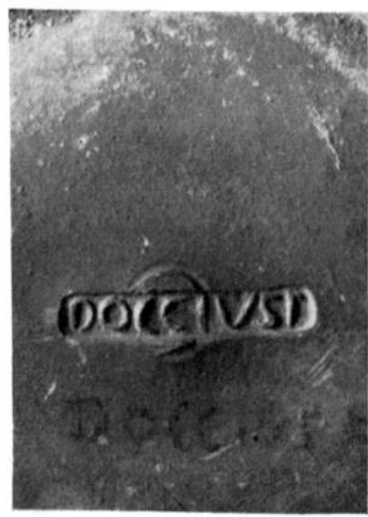

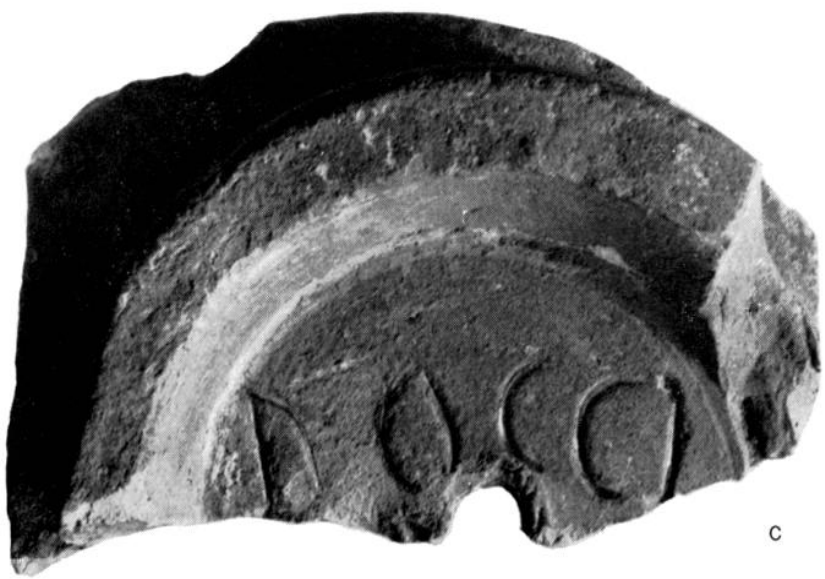

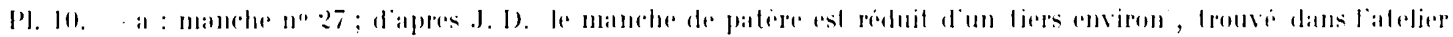

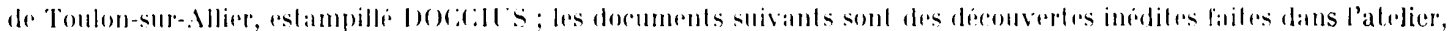

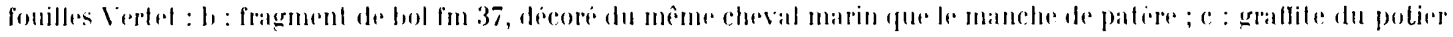

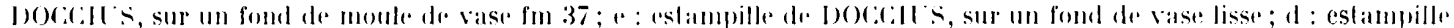

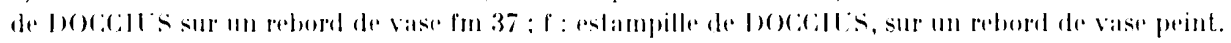



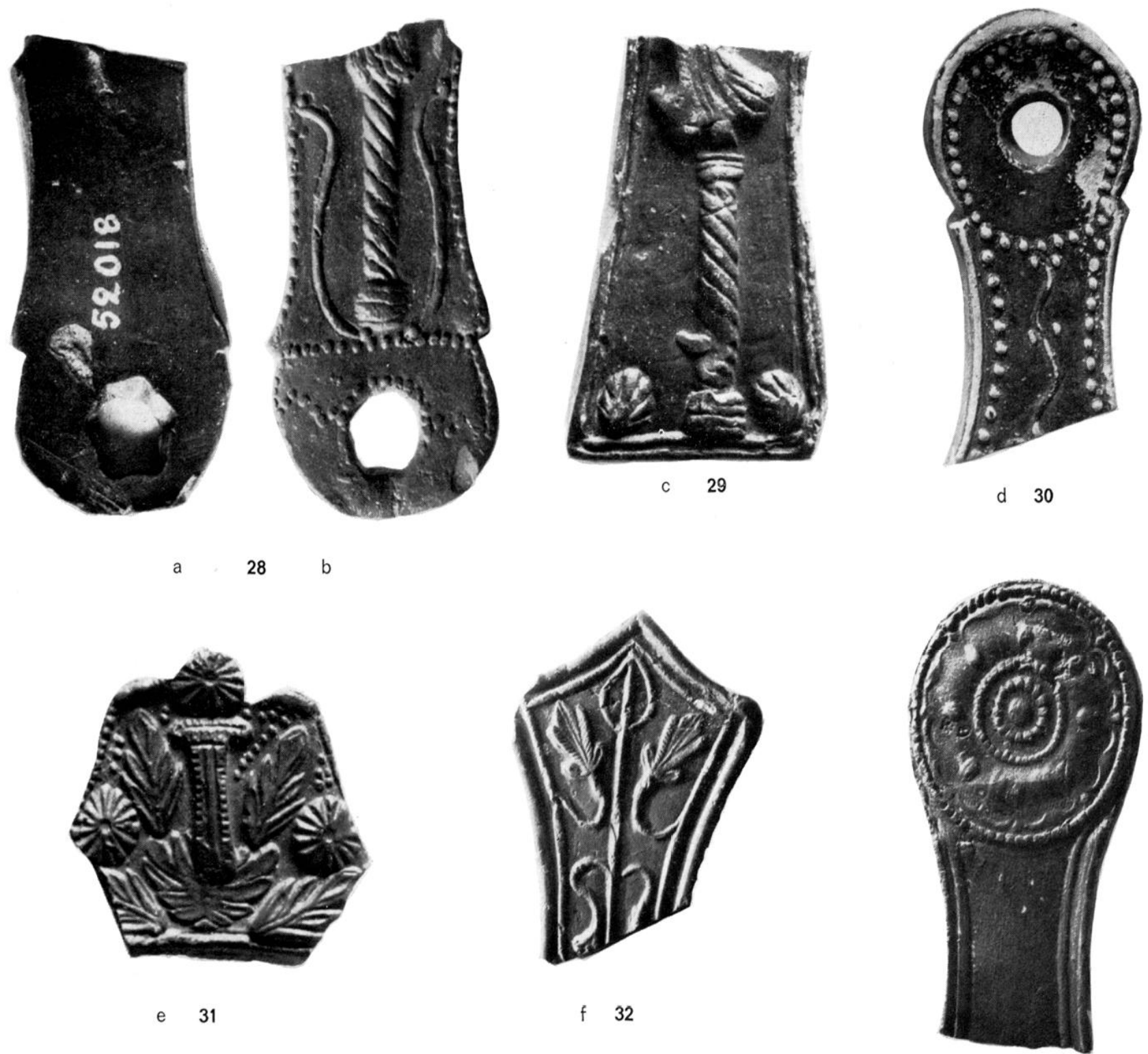

g $\quad 33$
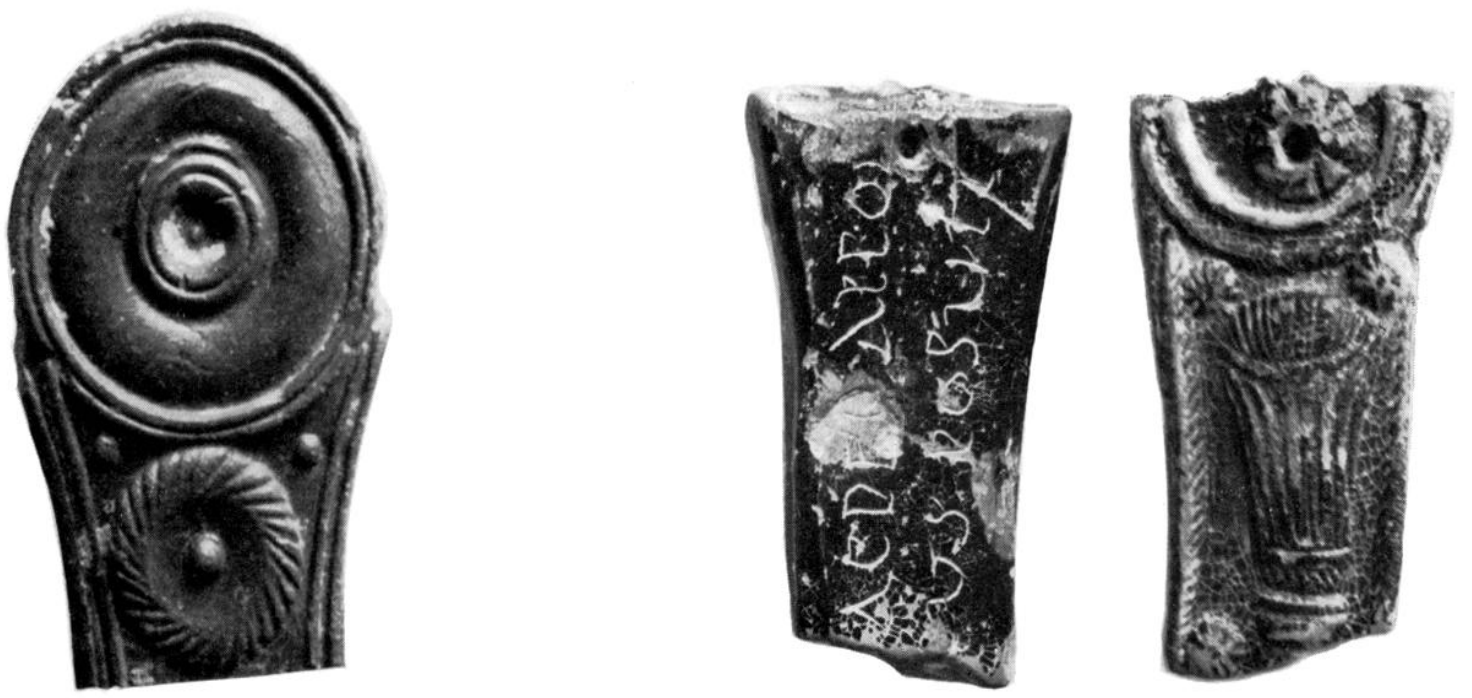

h 34

35

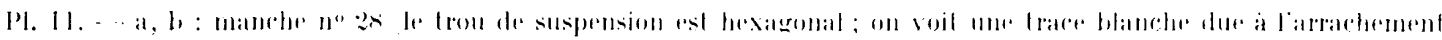

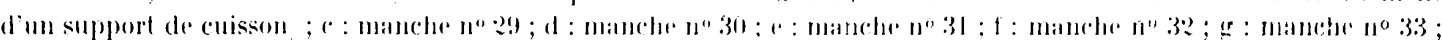

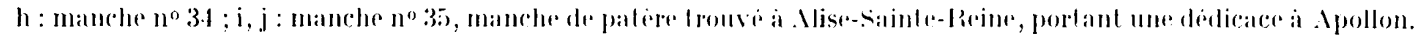




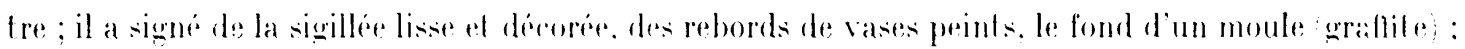
periode anlonine. P. 10, c. d. r. f.

Ia photo 10 he represente un exemplaire. Irouvé dans nos fouilles de Toulon-sur-Allier, du mime rheval marin que l'on voil sur le manche. no 27 , reduit d'un liers sur le dessin. pl. 10 a.

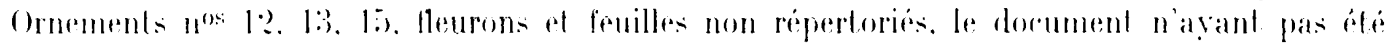
retrourió.

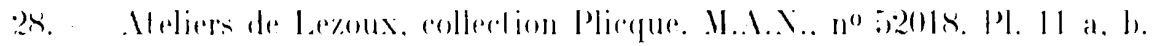

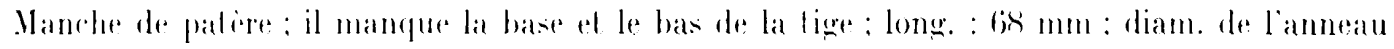

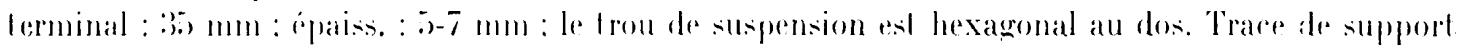
de arisions.

Areile rose : veruis rouge de la lerre sigillee.

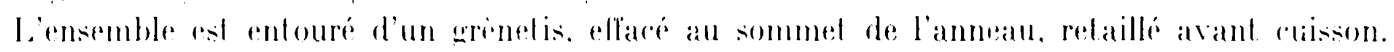

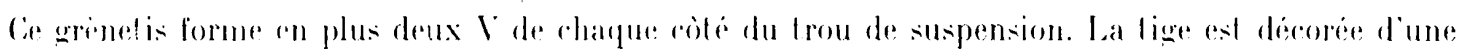
colomere de la base de laquelle parlent deus lignes onduleses traces a main levere lerminese par un point a rhaque extrimitr. sur le chapritean. masque de Pan, dont il ne reste que la barbe : a noter. de petils onglets. sur les lores de la base de la colonne.

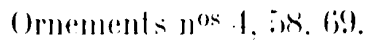

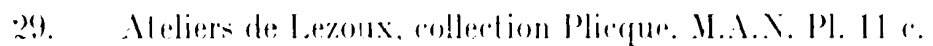

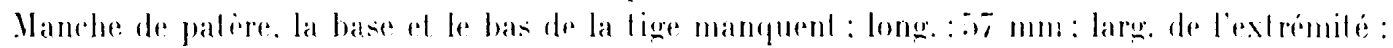
11 mm! ; épaisis. : (j-9) mm.

Iroile rose : vernis rouge de la lerre sigillée.

l'ne double moulure entoure lensemble. Lexlremile rectiligne a ses angles marques de deux coquilles. sur la lige. unc colonne: sur eelle colonne. une femme drapee Vietoire? dont il ne reste que la parlie inférieure.

(Ornements nos 10, 46. :\%) (iti.

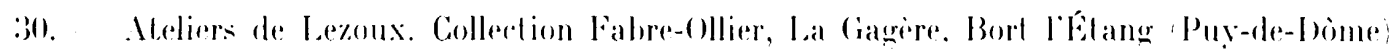
川. $11 \mathrm{~d}$.

Vanche de patiere : il manque la base el le bas de la tige : long. : li2 mm : diam. de l'anneau

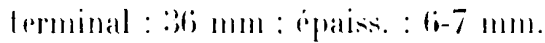

Terre rose. surface noire. brillante. sauf sur les relicfis ou alle est rose.

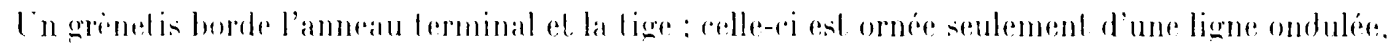

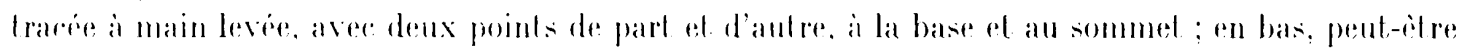
amorese diune feuille.

Ornement no lis i?

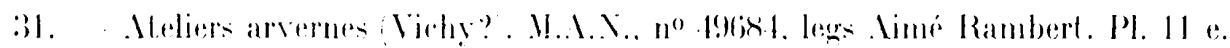

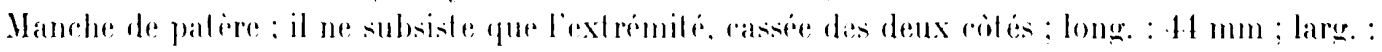
4li mmo : ipaliss. : 1-1; $111 m$.

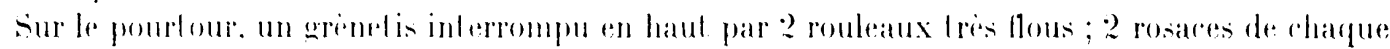

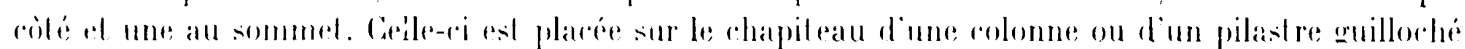

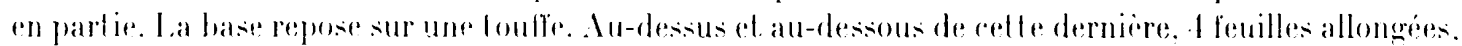

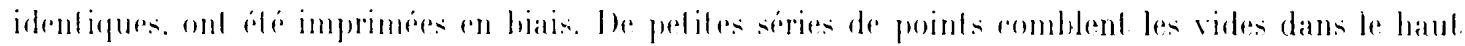

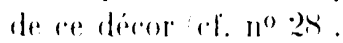

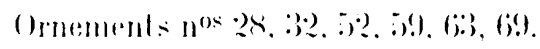

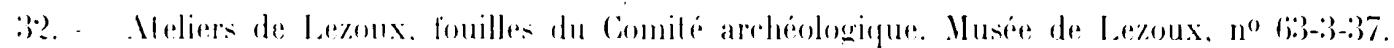
Pl. 11 i. ¿)-(i mm1n.

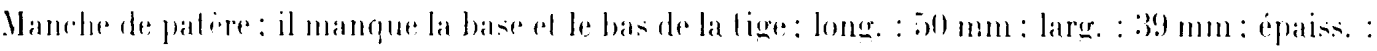




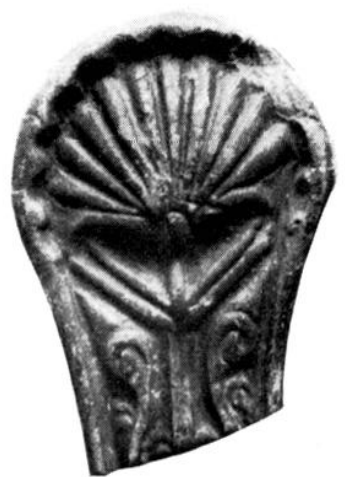

a 36

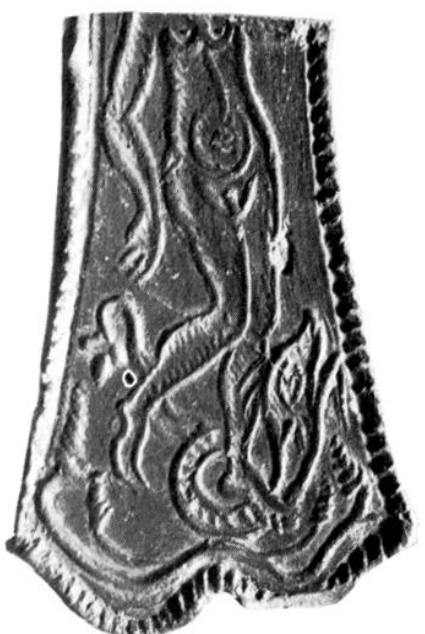

b 37

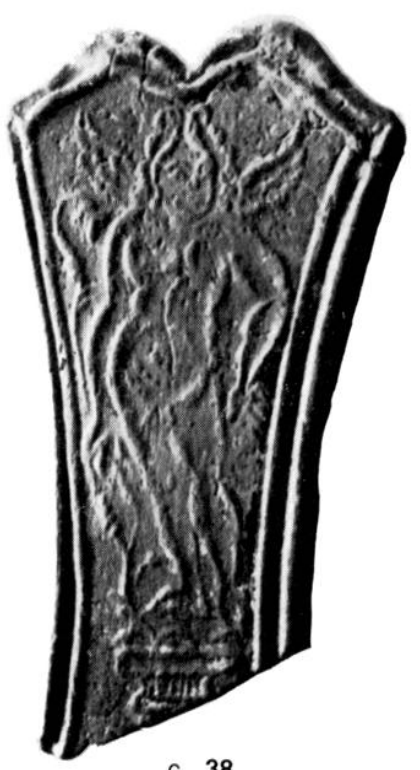

C 38
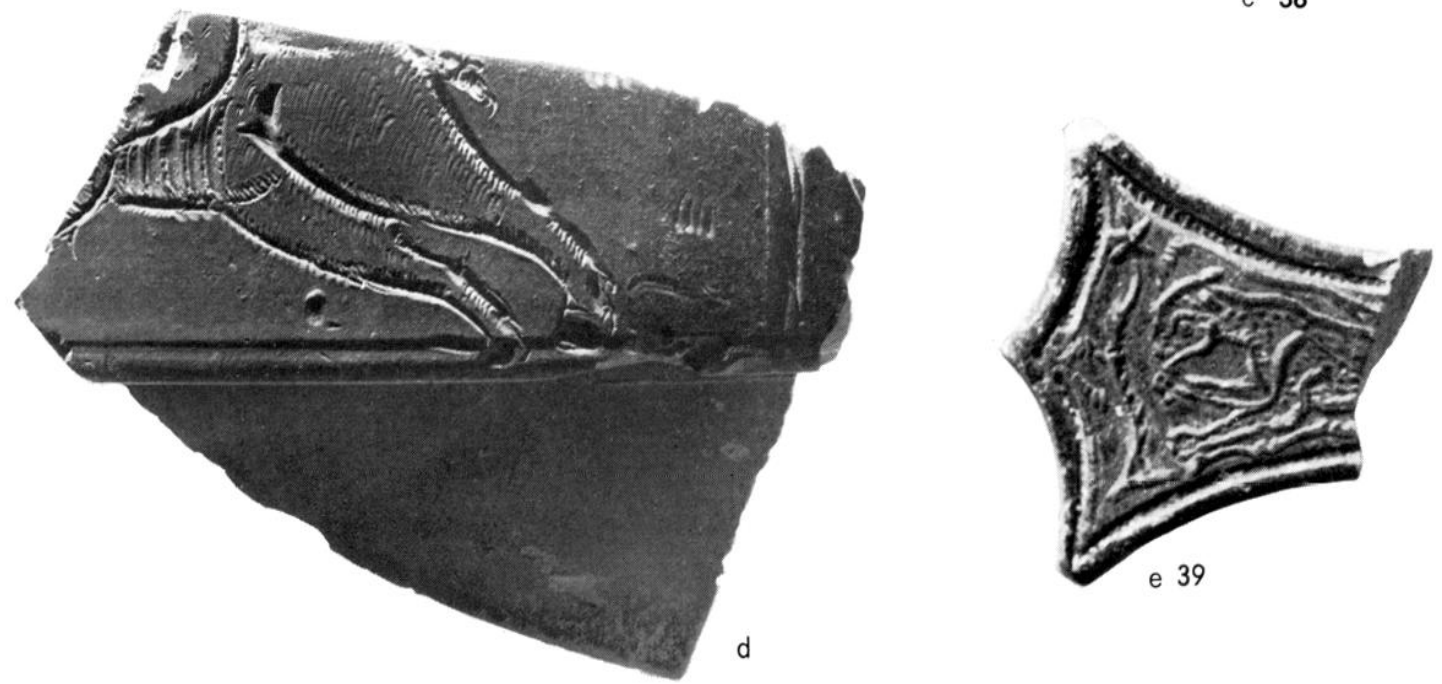

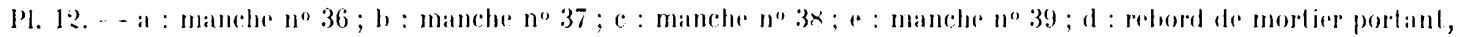

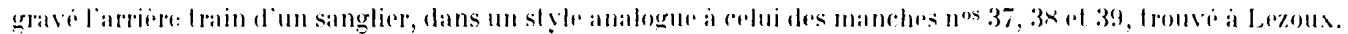

Aroile rose: : vernis rouge de la lerre sigillioe.

L'ensemble es entoure d'une double moulure. celle de l'intérieur étant plus efroite. l'n axe

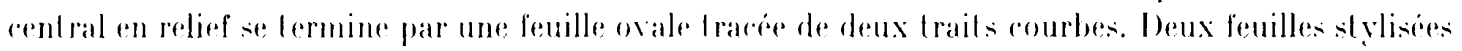
se rallachent de part el d'autre a la moulure par un peliole courbe. leux autres petioles partent. en sens inverse de la tige centrale vers le bas. ornes probablemenl de fleuroms.

()rnements $=$ nos:30, (6);.

3:). Neliers du Centre de la Gaule sansorigine. Muse de Moulins. Pl. 11 g.

Areqile rose vernis rouge de la lerre sigillér.

L'anneau terminal est entouré d'un grenelis : pas de lrou de suspension. I e décor est une grande marguerile aux perales largement étales. el au cour composé de deux cerces de grenel is el d'une: rosace l res emprilée. La lige est longée diune double moulure. le centre set lisse.

Grnement no 606 marquerite). 


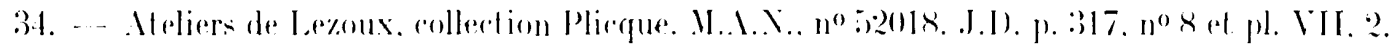
Pl. 11, h.

Manche de palere: il manque la base el le bas du manehe : long. : (ji) mm : diam. de lanneau terminal : $10 \mathrm{~mm}$ : ipaiss. : $8-10 \mathrm{~mm}$.

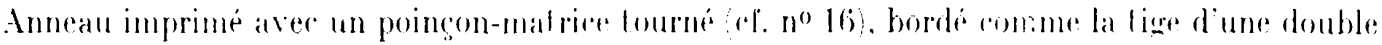

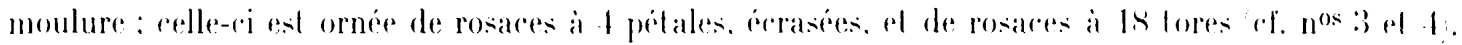

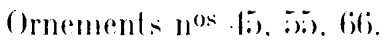

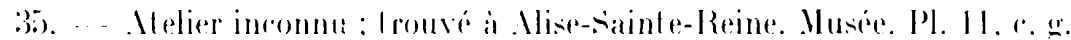

Manche de patire: la hase manque: long. au cenlre : 5o mm : epaiss. : $7.3 \mathrm{~mm}$.

Areile rougeal re. I res fine: vernis mélallise noir mal. disparu sur les reliefls.

L'extremile est decoré d'un double demi-cerele limbre d'une rosare a s' pétales. percé d'un pelil trou. La tige est bordee de deux palnes en partie ellaceses a a centre une corbeille tressée, encadrée de rosares a 10 perlates.

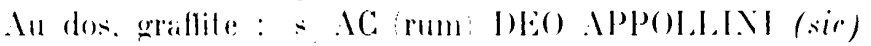

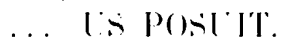

Ornement $n^{\circ} 80$, palmes et ronettes non rópertoriós.

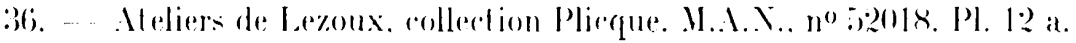

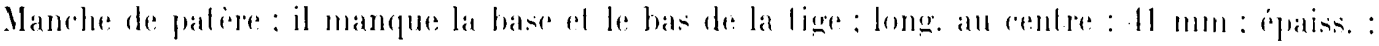
(i)-10 $\mathrm{mm}$.

Aroile rose : vernis rouge de la lerre sigillée.

L'extremile du manche est oreupe par une coquille : la lige semble décoré par un ormement en forme d'Y ; de chaque rote. des liges de fougrere ou des vrilles de vignte.

Ornements nos 71.34 .

37. -... Ateliers de Le\%oux. fouilles Vertet 1961, ansiruction de la maison Mathonniore, II. S. Musee de Iezoux. Pl. 1: h.

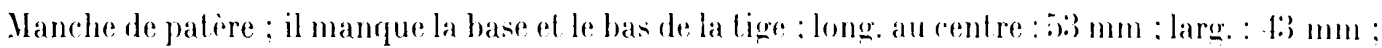
epaiss. : $7 \mathrm{~mm}$.

Argile rose : vernis rouge de la lerre sigillée.

Manche sorti d'un moule grave; sur la moulure qui entoure l'ensemble. hachures. Au rentre,

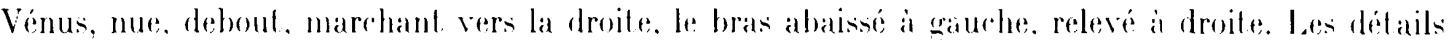
analomiques sont soulignes : seins, nombril enloure d'un cereles sexe. le pied droit repose sur un monstre marin dauphin?. dont la queue s'enroule et se lermine par une nageoire trilobé. Audessous, sarment avece vrilles.

Ornements $\mathrm{n}^{\mathrm{os}} 1,39$ animal marin grave:

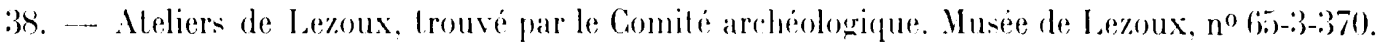
Pl. $12 c$

Manche de patiere : il manque la base et le bas de la tige : long. au cent re : $62 \mathrm{~mm}$ : large. : fi) mm ; ipaisis. : $7 \mathrm{mmm}$.

Manche sorli d'un moule gravé.

Tne double moulure enloure lensemble. Au renlre. Amour nu, deboul de fare ; le trace de

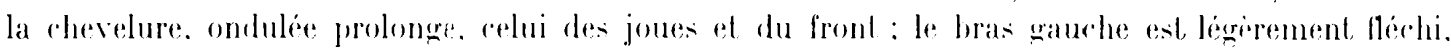
le droit allongé le long du corps saisit la ville d'un sarment qui śaleve d'un cratire : de relui-ri, seule subsiste la partie superieure. Te chaque ipaule solive une aile.

()rnements nos:? (i), (i)i.

39. - Ateliers de Lemoux, collection Plicque. II..... Pl. 12 e.

Manche de patiore: il manque la base el le bas de la tiene. Longr. an centre: $10 \mathrm{~mm}$. 
Manche sorti d'un moule gravé : sur la moulure qui entoure l'ensemble hachures. Au centre, une panthere courant vers la gauche : au-dessus. devant et au-dessous delle. sarments avec des vrilles et une feuille.

Ornement: nos 14,39 .

\section{RḰPERTOIRL: DES MOTIFS}

1. -- Vénus nue, légirement penchée vers la gauche. Son chignon, d'où pendent trois mirches sur son épaule, est trés proéminent; de sa main droite. elle retient une draperie qui descend de ses hanches et s'enroule aulour de ses jambes. Elle éleve la main gauche a la hauteur de son visage. Sous ses pieds, une plateforme relevée à gauche. Au-dessous, un masque masculin de face, chauve. barbu et moustachu. Xi J.I), ni OSW. ne signalent les méches qui descendent sur l'épaule. Nous pouvons ici retracer l'évolution du sujet:

$1^{0}$ poinçon complet : la déesse regarde son visage dans un miroir : J.I). 179. (OSW. 302-30:3: -.. 2o le miroir disparait, il n'en subsiste qu'un arc de cercle : J.L. 179? (0.SW. a loujours dessiné la main complete); ici, motif no 1. pl. 15. manche $9 ; \ldots$ - $3^{\circ}$ la main est remodelée, la paume ouverte en avant, les doigts sont retracés. J.I). 179 a, OSW. pl. XVI. Ici motif 1'. pl. 13 et 15, manches 10. 11 .

Vénus et le masque sont imprimés avec un seul poinçon. L'assemblage des deux motifs apparail. triss lòt, dis le début du ${ }_{1}$ e siècle (BUTRIO) el a peut-itre un sens religrieux.

Vénus : manches 9, 10, 11, 12,:37 (gravé..

J.I). donne un molif plus grand et un plus petit: osill. 306i. le plus proche semble-t-il. est attribué par l'auteur à I.IBERT's's et BLTRIO.

2. I)essin gravé d'un trait habile. Le theme de l'amour vendangeur est fréquent. cl. par ex. osW., pl. XXIII-XXIV : cependant ce n'est pas une copie.

Amour : manche $3 x$.

3.-.- Hercule, debout, de face. lenant sa massur contre son bras droit; motif tris effare: le bas du corps manque.

Hercule : manche 26 . pl. 13.

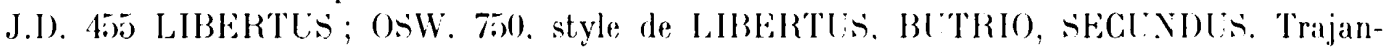
Hadrien.

3. - Hermis de Pan, de face : da la main gauche il porte la syrinx a ses lievres : de la droite. il tient un pedum, en forme de trompette. sion ventre est bien modelé. mais le moulage notamment celui de la trite, n'est pas bon.

Pan : manches nos 1:3, 14, pl. 1:3 et 15.

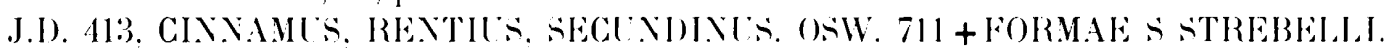
lladrien, Antonin.

4. - Masque de Pan, tourné à gauche : re motif a èté surmoulé bien des fois et cela a donné des varianles dans le détail de la barbe notamment.

Pan : manche 21, pl. 13 et 15.

J.I. (67) el OSW. 1214 ne distinguent pas les varianles. Ce molif semble avoir été employé surtout à la période antonine.

5. -... Masque de Pan, variante.

Pan : manche 22, pl. 13 et 1 i). 
6. Masque de Pan, variante.

Pan : manche no 23 , pl. 1:3 et 15.

7. IIomme nu, la jambe gauche lléchie, la droite tendue, le bras gauche levé au-dessus de la tite, le gauche au niveau du visage, qui semble regarder en bas a droile.

Wanche $\mathrm{n}^{0} 25$, pl. 13 et 15 .

J.I). 382 (interprété comme un satyre dansant. Ce n'est pas certain). J.D., OSIV. GGP : ALBUCILA, IOENALIS, PATERNUS, Q I BALBINLS. Trajan - Antonin.

8. siline debout, tourné de trois-quarts vers la droite ; il se pourrait que sa tête soit ceinte d'un bandeau; ses lèvres, épaisses, serrent l'embouchure d'une double flùte. Seul le bras droit est visible. Le dos et la poitrine, les jambes insuffisamment imprimées, semblent, à tort, très étroits. Le ventre est rebondi. Lne draperie est nouée a sa taille, avec des plis schématisés ; l'extrémité des pieds a peut-être été cassée sur le poinçon.

silene: manches nos $18,19 \mathrm{pl} .13$ et 14 .

Ce motif n'a été répertorié ni par J.D., ni par ()SW.. qui donnent seuleınent une figure plus trapue et plus lourde J.D. 310. OsiW. 609. Iomitien. Ce molif me semble dater du débul du ${ }^{\mathrm{e}}$ (I.IBERT'T'S, ...). Haut. : :3) $\mathrm{mm}$.

9. Femme nue, debout, de face, le bras droit replié au-dessus de sa tête, le gauche, le long du corps, soutient peut-ître un objet.

Manche $\mathrm{n}^{0} 25, \mathrm{pl} .13$ et 14 .

Motif répertorié ni par J.D. ni par OSW., qui en donnent d'analogues (haut. : $40 \mathrm{~mm}$ ) mais aucun d'aussi petit (ici $17 \mathrm{~mm}$ ).

10. Femme drapée, marchant vers la gauche. Peut-être une Victoire?

Manche no 29, pl. 13.

11. -... Femme drapée, de face, la main gauche levée, l'autre tendue vers la droite; vraisemhlablement une Victoire, dont les attributs manquent.

Manche $\mathrm{n}^{0} 24, \mathrm{pl} .13$ et 15.

Non répertorié dans J.I). I)ans $0 \mathrm{SW}$.. mème type, mais plus grand : haut. : $39 \mathrm{~mm}$; ici, haut. probable : $34 \mathrm{~mm}$.

12 et $13 .-$ Gladiateurs à droite et à gauche.

Manche no 27 ; non retrouvé.

14. - Panthire.

Nanche $\mathrm{n}^{0} 39$.

15). - Cheval marin, sur un manche, $\mathrm{n}^{0} 27$, signé DOCCIUS', non retrouvé.

Sujet analogue sur des tessons de DOCGIUs provenant des fouilles de Toulon-sur-Allier, if. pl. $10 \mathrm{~b}$.

16. -.. Grand chien courant vers la droite ; a noter : le collier, dont les stries sont à peine visibles, et les paltes lendues.

Manche $\mathrm{n}^{0} 22, \mathrm{pl}$. 13 et 14.

J.1). 915; OSW. 1917 ; GGP. LIBERTL', IUSTLA, IANUARIS II, MASGELLI O, PATERNUS.

17. -..- Grand chien; différent du précédent par l'attache de la queue.

Manche $\mathrm{n}^{0} 2: 3$, pl. 13 .

18. Petit chien courant vers la droile : motif mal venu.

Manche $n^{0} 2 t$, pl. 13 et 14 . 

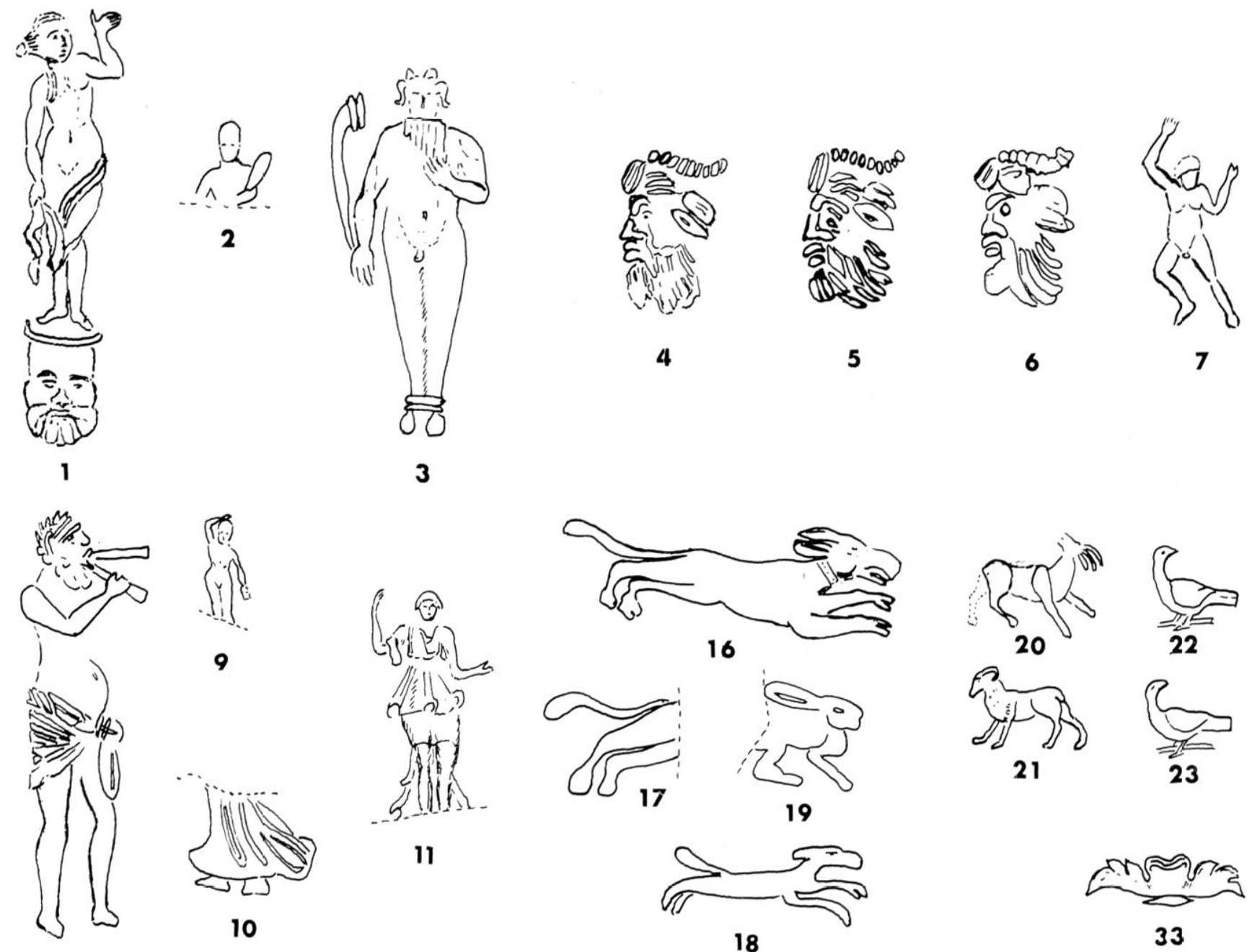

11
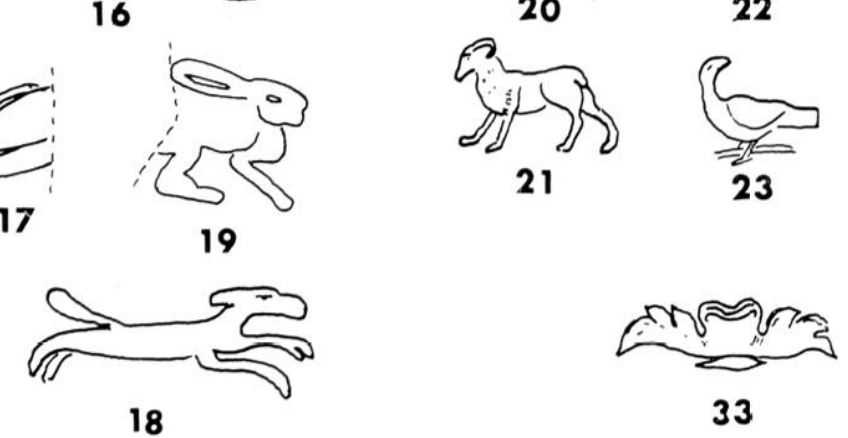

8
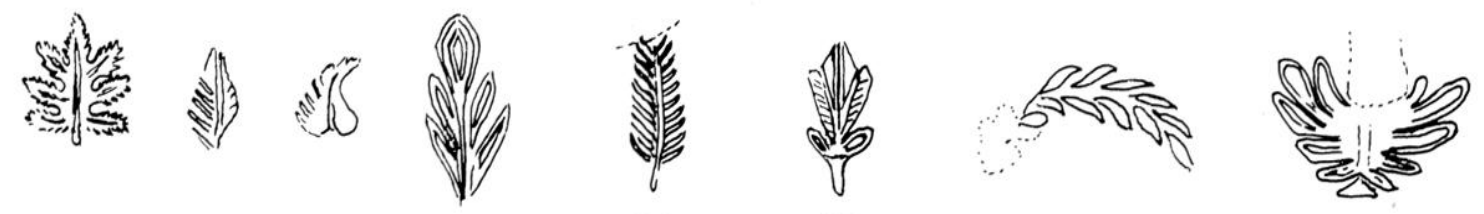

24

$\begin{array}{l:lll}25 & 26 & 27 & 28\end{array}$

29

30

31

32

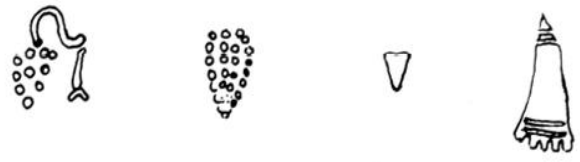

sic

36

$37 \quad 38$

40

41

42

43

$44 \quad 45$

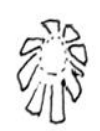

46 

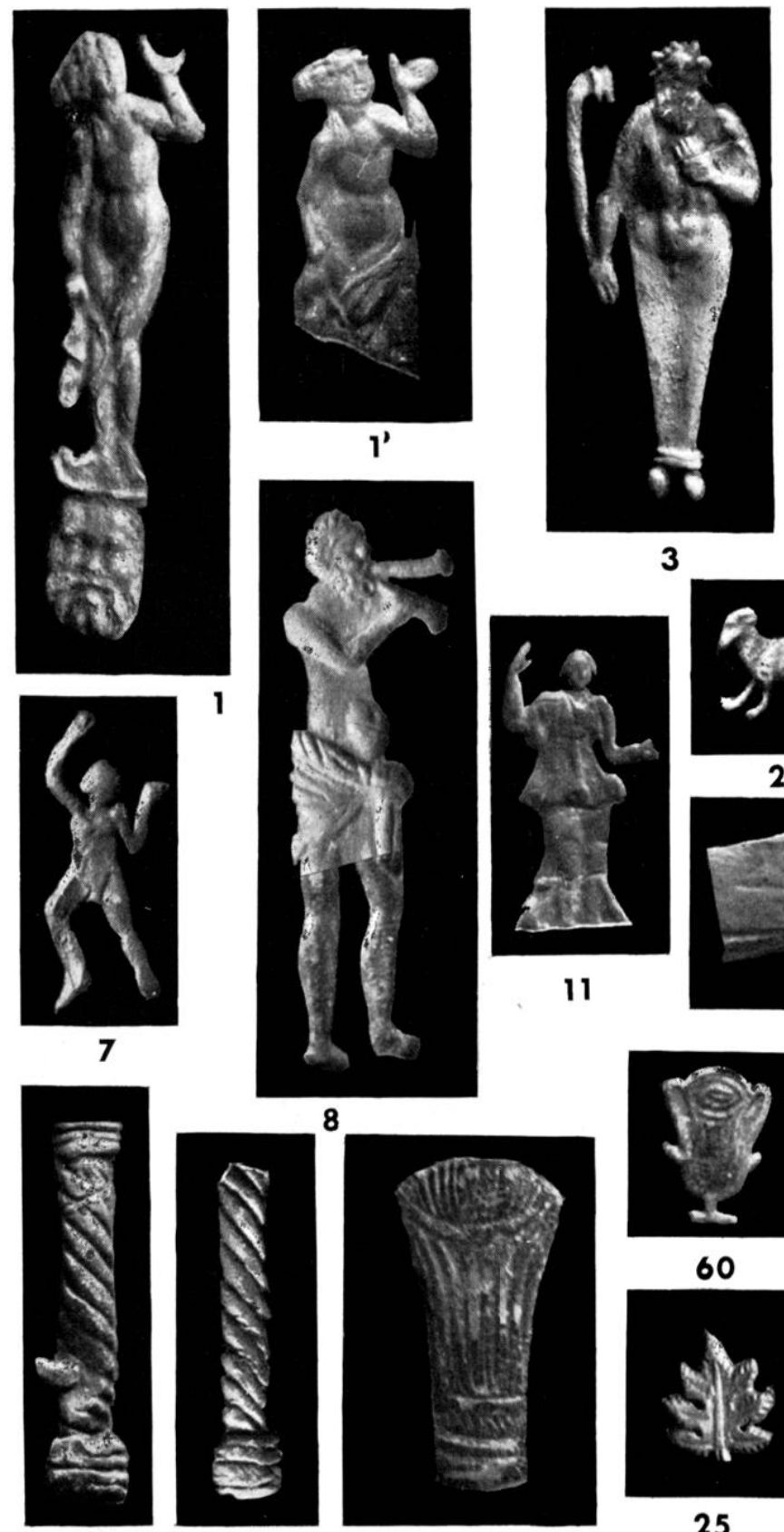

57

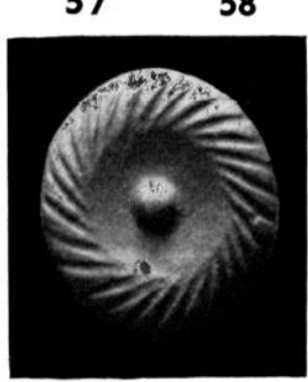

55

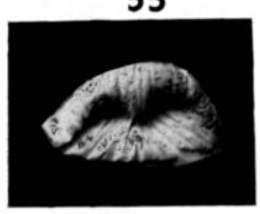

76

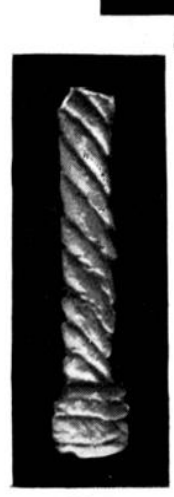

8
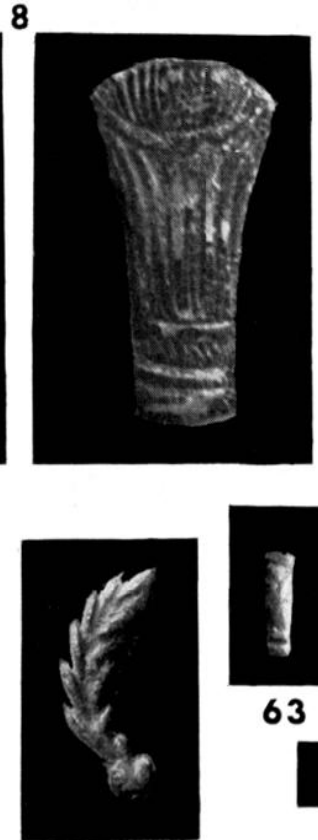

31

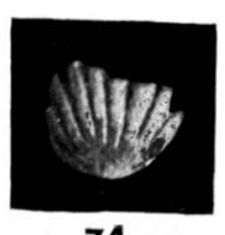

74

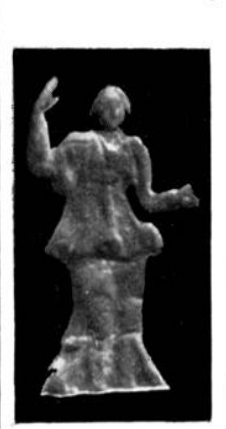

11
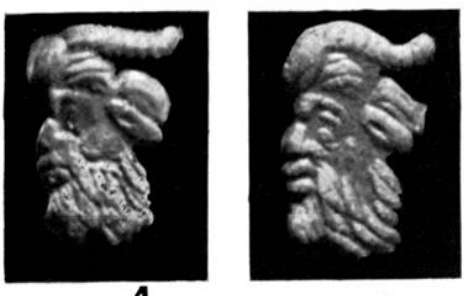

5
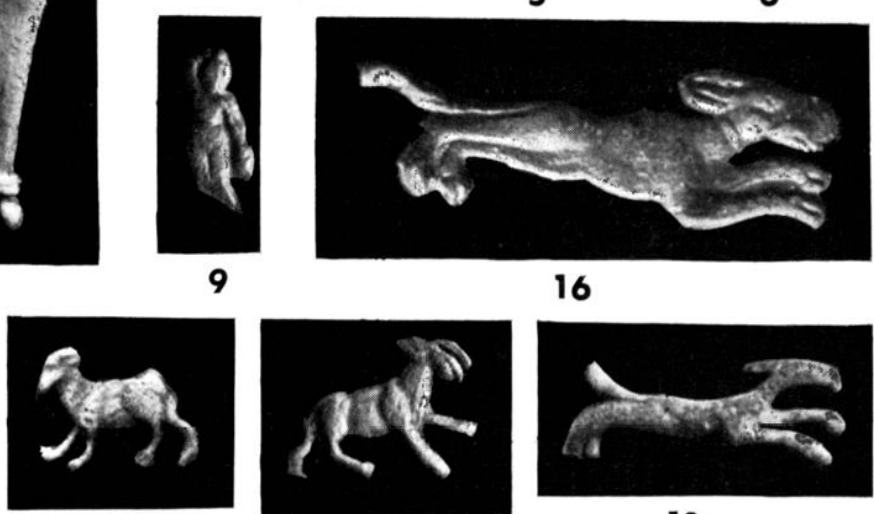

21
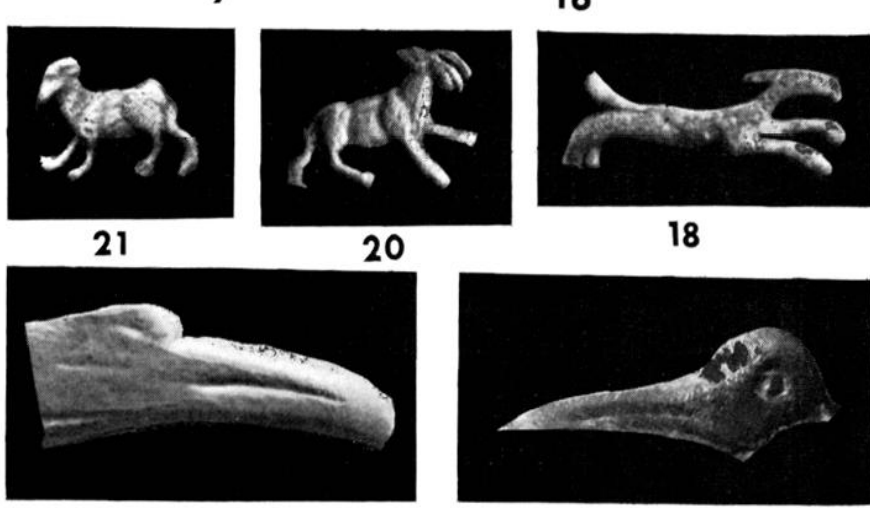

18

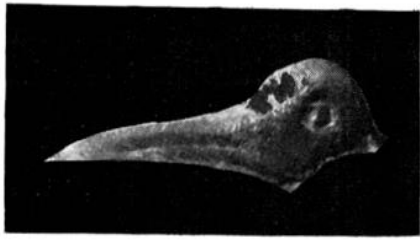

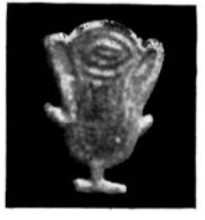

60

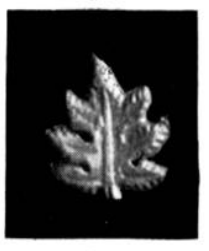

25
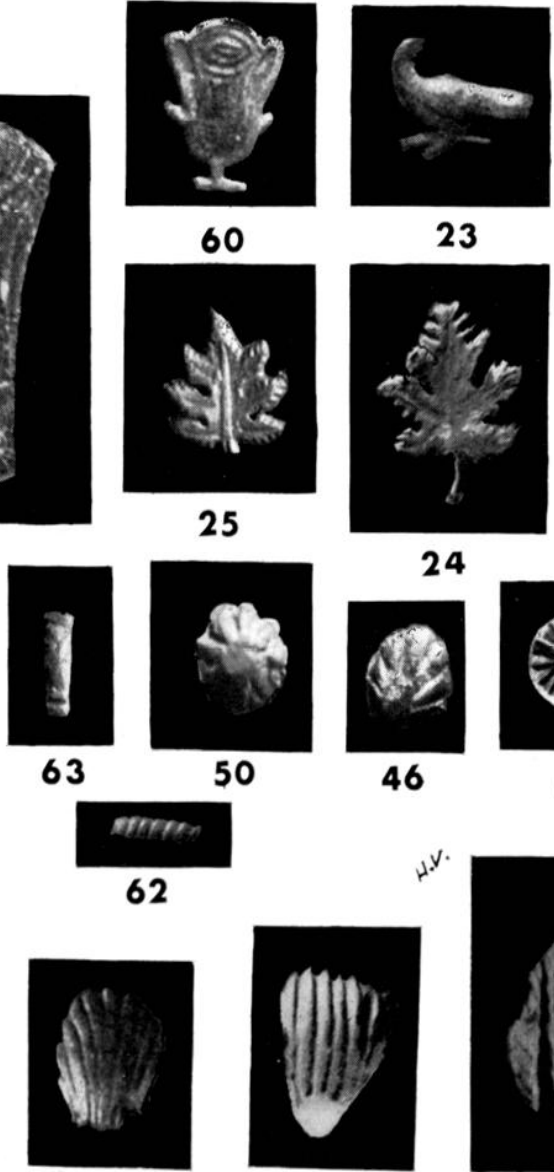

75
23
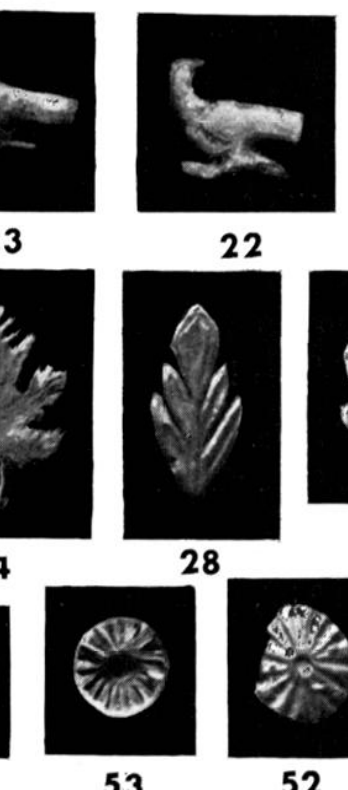

22

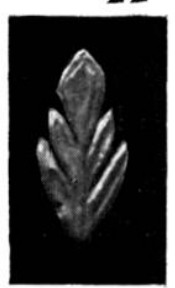

28

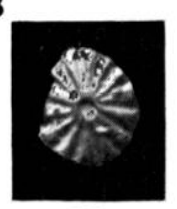

52

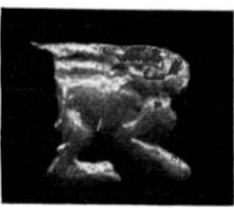

19
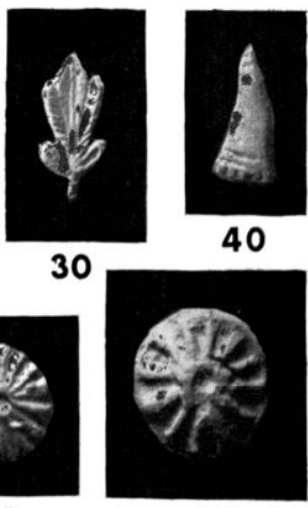

51

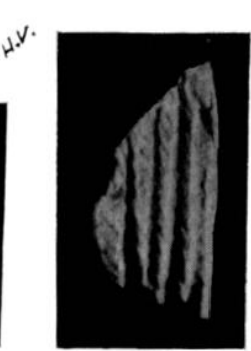

72

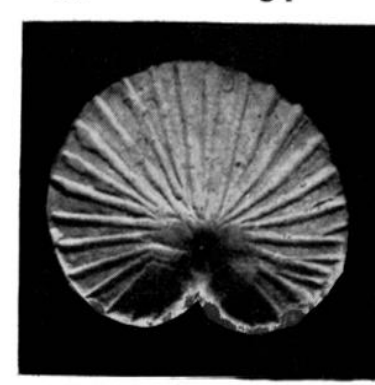

70

P'l. 15. - liepertoire photographique de molifs releves sur les manches et dans les moules. 
J.D. 919 ; OSW. 1940, GGP. ALBUCIUS, AUSTRUS, CENSORINUS, BUTRIO, DOEGGUS, ILSTI M, IASTUGA, LAXTUGISSA, PATERNUS.

19. -... Lapin tourné vers la droite.

Manche n ${ }^{\circ} 25$ (Vichy), pl. 13 et 14.

OSW. no 2061, PATERNUS, ANTISTIORUM, LAXTUGISSA.

20. . Chèvre marchant vers la droite, retournant la tête ; deux cornes et une oreille visibles. Manche no 13 , pl. 13, et 14 .

J.D. 890 ; OSW. 1834, GGP. LIBERTUS, BUTRIO, DRUSUs, MARTIU F, elc.

21. - Bélier marchant vers la gauche, la toison est marquée par de petits traits.

Manche $\mathrm{n}^{0} 13, \mathrm{pl}$. 13 et 15.

J.D. 895, OSW. 1868 (ces exemplaires sont plus grands que le nôtre), LIBERTUS, BUTRIO, style de ADVOCISUS et CENSORINUS...

22. - - Colombe tournée à gauche, regardant en arriere, perchée sur une brindille, queue horizontale.

Manche $\mathrm{n}^{\mathrm{0}} 11$, pl. 13 et 15 .

J.D. 1018 ; OSW. 2306, donnent des colombes dans une attitude analogue, mais plus grandes.

23. - Colombe tournée à gauche, regardant en arrière, queue horizontale, légère bosse sur le dos, variante du précédent.

Manche $\mathrm{n}^{0} 12$, pl. 13 et 15 .

24. - Feuille de vigne, dans le moule : haut. : $18 \mathrm{~mm}$, larg. : $16 \mathrm{~mm}$.

Manche $\mathrm{n}^{0} 3$, pl. 13 et 15 .

25. - Feuille de vigne, haut. : $13 \mathrm{~mm}$.

Manche $\mathrm{n}^{\circ} 17$, pl. 13 et 15.

26. - - Petite feuille droite, partie gauche plus large que la droite.

Manche $\mathrm{n}^{\circ} 15$, pl. 13.

27. -- Petite feuille arquée.

Manche $\mathrm{n}^{0} 15$, pl. 13.

28. - - Feuille droite a 5 folioles.

Manche no 31 , pl. 13 et 15 .

29. - Feuille.

Manche $\mathrm{n}^{0} 12, \mathrm{pl} .13$.

30. - Feuille stylisée.

Manche no 32 , pl. 13 et 15.

31. - Feuille arquée à 5 folioles extéricurs et 5 intérieurs et un terminal.

Manche no 9 , pl. 13 et 15 .

CGP : BUTRIO.

32. - Touffe?

Manche $\mathrm{n}^{\circ} 31$, pl. 13.

33. -- Touffe d'acanthe stylisée?

Manche no 8, pl. 13.

34. - Pousse de fougère ou vrille de vigne?

Manche $\mathrm{n}^{\circ} 36$. 
35. -.. Trois ornements ovoïdes?

Manche no 9 .

36. -.. Grappe de raisin ; il se pourrait que le motif soit imprimé avec un poincon composite, formé de la grappe d'un petit S et d'un ornement en Y renversé.

Manche nos $19,12 ?$, pl. 13.

37. Grappe.

Manche nos 16,17 ?, pl. 13.

38. - - Vrille en forme de triangle.

Manche $n^{\circ} 16$, pl. 13.

39. - Grappes et vrilles gravées.

Manches nos $7,37,38,39$.

Assemblage de points ou de rosaces en grappe : $3,4,21,26$.

40. - Ornement triangulaire, clochette? bourse?

Wanche $\mathrm{n}^{\circ} 15$, pl. 13 ei 14.

41. - Rosace à 9 pétales, avec trou central, diam. : $4 \mathrm{~mm}$.

Manche $\mathrm{n}^{\circ} 17, \mathrm{pl} .13$.

42. - Rosace à 9 pétales, diam. dans le moule : $\overline{\mathrm{mm}}$.

Manche no 6 , pl. 13.

43. . Rosace à 10 pétales, diam. : $5 \mathrm{~mm}$.

Manche no $15, \mathrm{pl} .13$.

44. - Rosace à 10 pétales, diam. : $7 \mathrm{~nm}$.

Manches nos 7,11 , pl. 13.

45. - Rosace à 4 pétales, diam. : $2,6 \mathrm{~mm}$; souvent écrasée, prend la forme d'un gros point. Hanches $\mathrm{n}^{\text {os }} 3,4,24,34$, pl. 13 .

46. --- Rosace tris oblique, peut-être petite coquille ; plus grande dimension : $10 \mathrm{~mm}$.

Manche no 29 , pl. 13 el 14.

47. Rosace à 6 pétales, diam. : $10 \mathrm{~mm}$.

Manches nos $11,13, \mathrm{pl} .14$.

18. Rosace à 7 pétales, bord double, diam. : $10 \mathrm{~mm}$ environ.

Manche no 25, pl. 14.

49. -... Rosace à 7 pétales, diam. : 9-10 $\mathrm{mm}$.

Manche no 26, pl. 14.

50). - Rosace à 9 pétales, diaın. : $10 \mathrm{~mm}$ environ, tronconique.

Manche no 21 , pl. 14 et, 15.

5) bis. Rosace trés ecrasée; manche no 26 .

51. .... Rosace à 12 pétales, diam. : 15 $\mathrm{mm}$ environ, dans lo moule.

Manches nos 3,4 , pl. 14 et 15.

5). Rosace à 14 pélales, diam. : $11 \mathrm{~mm}$ environ.

Manche no 31, pl. 14 et 15. 


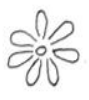

47

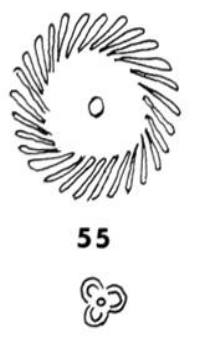

56

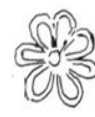

48

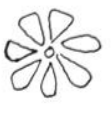

49

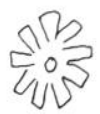

50

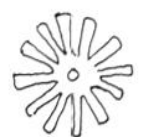

51

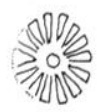

52

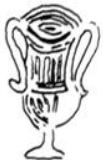

60

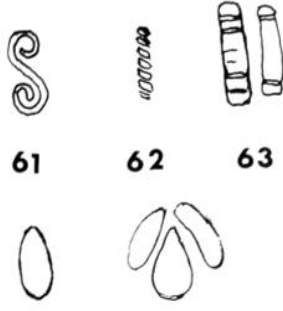

64

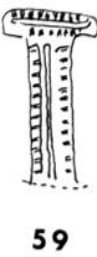

58
0000000000

67
0000000000000

68

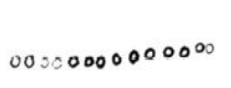

69

Pl. 14. - Tiepertoire des motifs releves sur les manches de pateres et dans les moules.

¿i. Rosace a 16 petales? quelques-uns sont probablement, asses sur le poincon matrice, diam. : 10 mm environ, dans le moule.

Wanche no $n^{\circ}$, pl. 14 et li).

i). Petit rerrle, diam. : :3 mm environ.

Janches nos $9.10,13,14,15,16$, pl. 13.

5i). Cirande rosace a 18 lores, dian. : 21 mm sur l'épreuve, 2l d dans le moule.

Nanches nos $3,4,34$, pl. 14 et 15.

56. Fleurelle a 3 pelales ; plus grande dimension : 5) mon dans le moule.

Manclue $n^{\circ} 8$, pl. 14.

57. Colonne.

Hanche no 29, pl. 14 et 15.

58. Colonne.

Manche $\mathrm{n}^{\circ} 2 \mathrm{~s}, \mathrm{pl}$. 14 et 15 .

59. Colonne, on pilastre.

Hanche no:31, pl. 14.

60. Cratire ; est représentée par des ovales roncentriques, la panse est godronnée.

Manche no 42 , pl. 14 et 15.

Sur le manche 38 , rratère dessiné au trail.

61. Girand $\mathrm{s}$, long. : $11 \mathrm{~mm}$.

Hanche no 25, pl. 14. 
62. Torsade, long. : $9 \mathrm{~mm}$.

Manche no 9 , pl. 14 et 15 .

63. Houleau. long. : $12 \mathrm{~mm}$ dans le moule, 10.5 sur l'épreuve, environ.

Vanche $\mathrm{n}^{\mathrm{os}} 6$ (moule), 17 , pl. 14 et 15 .

64. . Ornement ovoïde, longr. : $8 \mathrm{~mm}$.

Ilanche no 9, pl. 14.

65. Trois ornements?

Manche no 9 , pl. 14.

66). Double moulure le long de la tige.

Manches $\mathrm{n}^{\mathrm{os}}: 3,4,6,7,10,13,14,15,16,24,32,33,34$.

67. Grinetis à gros poinls, diam. : $3 \mathrm{~mm}$ environ.

Manches nos 19, 32(?), pl. 14.

68. Grènetis a points moyens, diam. : $2 \mathrm{~mm}$ environ.

Manches nos 19, 22 (?), 27 (?), 30 (?), pl. 14.

69. - Cirinetis a points fins, diam. : $1 \mathrm{~mm}$ environ.

Manches nos $8,20,22,23,25,28,31,33$, pl. 14.

70. Coquille, imprimée sur l'anneau terminal.

Manche no $7, \mathrm{pl} .14$.

71. - Coquille, imprimé sur l'anneau terminal.

Manche no 36 .

72. -... Coquille, imprimée à l'extrémité du manche; il manque la partie droite.

Manche $n^{\circ} 6$, pl. 14.

73. - Coquille sur l'épaulement.

Manche $\mathrm{n}^{\circ} 6$, pl. 14.

74. -.. Coquille sur épaulement.

Manche $\mathrm{n}^{0} 22$, pl. 14.

75. Coquille sur l'épaulement.

Manche nos 12,13, pl. 14.

76. - Coquille sur épaulement.

Manche $\mathrm{n}^{0} 7, \mathrm{pl} .14$.

77. C Coquille sur épaulement, très abîmée par le découpage du moule.

Manche no 17.

78. - Tète d'oiseau, bec, allongé, wil rond, sur le bec du manche.

Manches $\mathrm{n}^{\mathrm{s}} 6,17, \mathrm{pl} .14$ (tourné vers la gauche).

79. Tète d'oiseau, œil allongé.

Manches nos 3,4, pl. 14.

80. -. Corbeille en osier.

Manche no 35 , pl. 14 . 


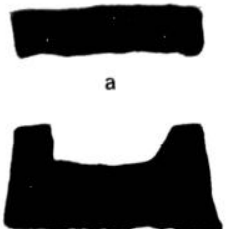

b

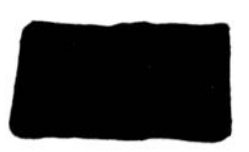

c

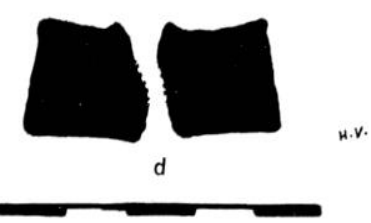

3 a : profil d'un manche $\left(n^{\circ} 37\right)$;

b : profil du moule no 5 irclevé sur le manche! ;

c : profil du prototype $n^{\circ} 1$ la face d'impression, plus large, est tournée vers le bas);

d : profil du prototype no 2 , relevé au niveau du trou de suspension.

4 Formes des extrémités de manche.
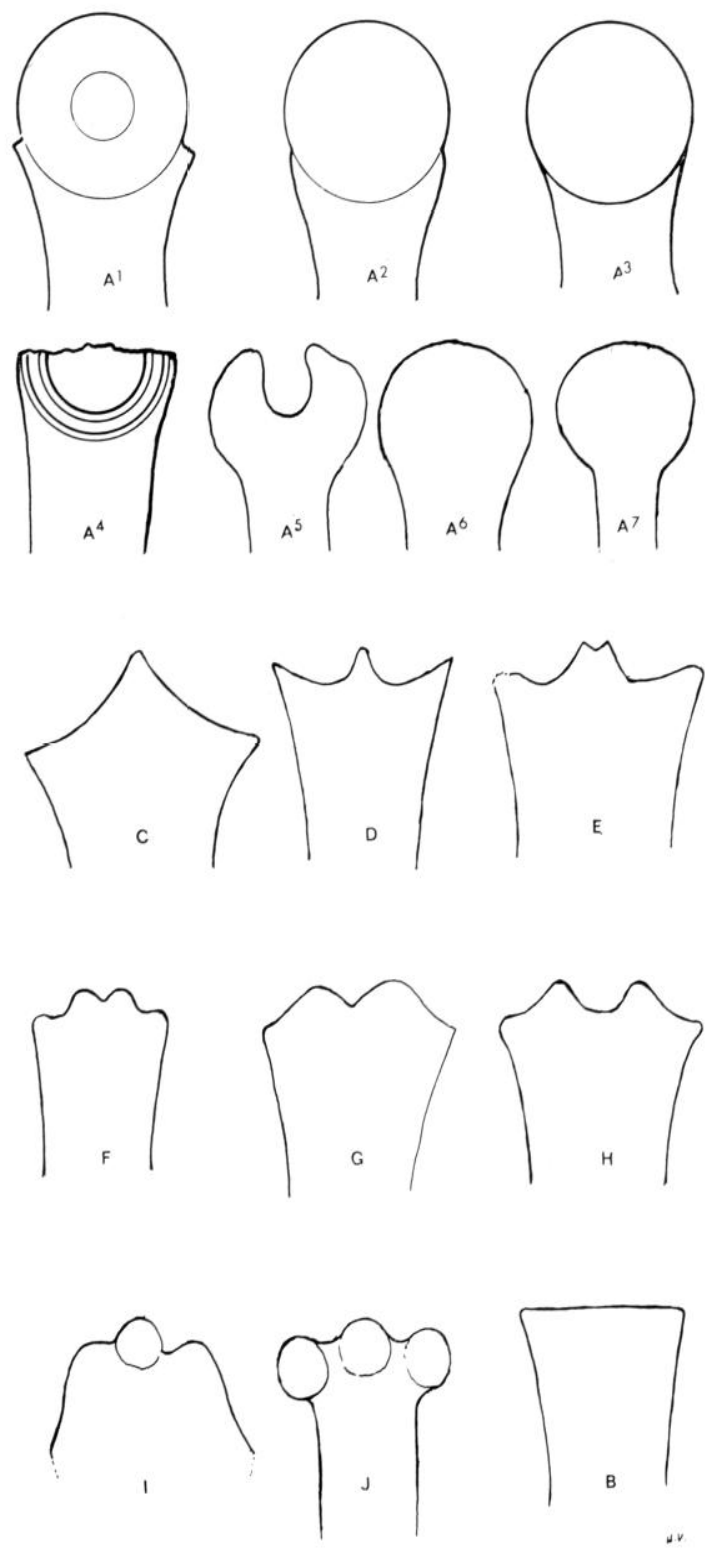

\section{Forme des extrémités de maNche}

Sur 39 documents répertoriés, 34 ont une terminaison intacte ou reconstituable (fig. 4).

La forme la plus courante (quinze exemplaires) est l'anneau terminal : $\left.n^{\circ s} 4,5\right), 7,8,10,11,13$, $14,16,20,28,30,33,34,35$. Nous en avons donné les variantes :

la tige se termine en général par deux onglets qui enserrent le bas de l'anneau (figr. 4, al : $\left.\mathrm{n}^{\text {os }} 10,13,14,16,28,30\right)$; parfois ces onglets sont eflacés : fig. 4, a2: $\mathrm{n}^{0} 34$ ) ou disparaissent complitement (fig. 4 , a3 $: \mathrm{n}^{0}$ 7). Sur un exemplaire d'Alésia (fig. 4, a4: $\mathrm{n}^{0}$ 33) l'anneau semble avoir été coupé, pour obtenir une terminaison rectiligne. Sur le $n^{0} 20$ (fig. 4 , a') : $n^{0}$ ) ), il a été ouvert jusqu'au trou de suspension, et se transforme en deux cornes. Le $n^{0} 36$ (fig. 4, a : $\left.n^{0} 6\right)$ est timbré d'une coquille, comme le $n^{0} 23$; mais le décor ne remplit pas tout le cercle et l'anneau est complété par d'autres 
décors qui rejoignent ceux de la tige. La mème chose s'est passée sur le no 28 , où l'anneau est coupé par un grènetis. Enfin, le moule 5 (fig. $4: n^{0} 7$ ) a une liaison anneau-tige plus rigide.

La terminaison rectiligne (fig. 4 b) se trouve sur 5) exemplaires; six ont trois pointes (fig. $4 \mathrm{c}$ : nos $6,23,24,26,32,39$ ) et quelques autres formes ne se rencontrent qu'a un ou deux exemplaires (fig. $4 \mathrm{D}: \mathrm{n}^{0} 23 ; \mathrm{F}: \mathrm{n}^{0} 1 ; \mathrm{F}: \mathrm{n}^{0} 27 ;\left(\mathrm{i}: \mathrm{n}^{0} 37 ;\right.$ II $\left.: \mathrm{n}^{0} 9 ; \mathrm{I}: \mathrm{n}^{0} 31 ; \mathrm{J}: \mathrm{n}^{0} 24\right)$.

\section{Fabrication}

Plusieurs ateliers de potiers gallo-romains ont fabriqué des patères à manche moulé ou lisse : Gueugnon, rattaché au groupe arverne, et, sur les bords du Rhin, Strasbourg, Holdern, et d'autres. Mais dans l'état actuel de nos connaissances, les ateliers de la vallée de l'Allier fournissent des exemplaires plus nombreux et plus variés. Serait-ce parce que les copies de vaisselle en métal -. bien moins fréquentes, certes, dans la production que les bols el assiettes sigillées - y ont eu une certaine faveur?. I)éjà au début du Ier siècle, Saint-Rémy-en-Rollat, par exemple, avait mis sur le marché des casseroles à manche cylindrique. Mais c'est surtout à partir du début du ${ }_{\mathrm{I}}^{\mathrm{e}}$ siècle que l'on rencontre des anses d'oenochoé, des oreilles de patère, des copies de lampes en bronze. Il est possible que les potiers aient surmoule directement des manches de métal, mais nous n'en connaissons encore aucun. D'après les exemplaires de leurs produits que nous avons pu recenser, ils ont été amenés à fabriquer eux-mèmes complètement l'objet. Avec les documents retrourés, nous pouvons suivre toutes les étapes de la fabrication.

Le potier modelait d'abord un prototype massif assez épais qui servait de matrice; nous en avons deux échantillons l'un de Lezoux, sans décor $\left(n^{0} 2\right)$, l'autre, de Toulon-surAllier ( $\left.n^{0} 1\right)$, porte une simple moulure sur son pourtour, sur une face. Si le dos n'est pas soigné, la face à imprimer est lissée soigneusement, ainsi que les côtés verticaux. Cétte face est un peu plus étroite que l'autre, pour faciliter son retrait après impression. Elle est badigeonnée de rouge - ainsi que les côtés - pour que l'ouvrier évite de se tromper au moment de la fabrication du moule : imprimer l'objet à l'envers donnerait un fond irrégulier, et dont les parois ne seraient pas obliques, ce qui est nécessaire pour obtenir un moule "de dépouille» (fig. 3).

Le potier laissait la plupart du temps ce prototype lisse ou peu décoré. En effet, d'éventuels décors se retrouveraient en creux sur les manches, alors que presque tous sont en relief, selon l'habiturle des rases sigillés. On peut supposer que la moulure visible sur le prototype $n^{0} 1$ et qui donnait un relief dans le moule a servi de guide pour imprimer un de ces grènetis, si fréquent autour des manche, et qu'elles n'apparaissait pas sur les épreuves. Cependant, deux exemplaires exceptionnels nous montrent que les prototypes étaient parfois ornés en creux. Les reliefs qui sont au fond du moule $\mathrm{n}^{0} 7$ ont forcément été obtenus par une matrice gravée de pampres. Ils reproduisaient ainsi les décors concaves, comme on peut le voir sur l'épreuve que nous en avons tirée (pl. 5, a et b). Le no 5 ( a aussi été fait avee un prototype orné. La forme des moulures longitudinales ne peut aroir été obtenue par un travail effectué dans le fond du moule. Il est done certain que le potier a modelé, de facon assez sommaire certes, les cercles, les traits, les têtes sur une matrice massive. 
Une fois le prototype séché et cuit, le potier en enfonçait la face peinte, à plat, de 5 à $8 \mathrm{~mm}$ dans une plaque d'argile crue, fine, bien travaillée. Il obtenait ainsi un creux reproduisant les contours du manche, et dont le fond etait habituellement lisse. Il ornait alors ce creux. Le plus souvent, il imprimait, comme dans des moules de vases sigillés, des poincons-matrices qu'il prenait dans son répertoire habituel : personnages, animaux, végétaux, objets, motifs variés. Quelques motifs semblent particuliers aux manches : les grosses coquilles ( $\mathrm{n}^{\text {os }} 70-71$ ), la rosace ( $\mathrm{n}^{0}$ 5) ) mais il est possible que la révision du répertoire des motifs de la sigillée moulée y intègre ces décors. Parfois, le potier gravait une partie du moule ou le moule tout entier à main levée. Cette façon de faire est exceptionnelle dans la fabrication des vases sigillés, où elle sert surtout pour les pétioles de feuilles. Elle prend, sur les manches de patère, une place remarquable sur laquelle nous reviendrons un peu plus loin

Le: moule, un peu séché, était découpé avec une lame, dont les traces se voient nettement. Ce faisant, l'artisan ménageait une paroi dont l'épaisseur moyenne est celle des autres moules de vases ou de figurines contemporaines.

Les moules que nous arons entre les mains ne portent pas de nom de propriétaire ou de fabricant, comme cela se voit assez souvent sur ceux des vases ou des figurines. On notera seulement que le $n^{0} \bar{y}$ porte au dos les mêmes croisillons tracés dans l'argile crue que certains moules de figurines de Toulon-sur-Allier et de Vichy. Les fabricants dr manches de patères étaient donc bien les mêmes que ceux de la sigillée, utilisant les mêmes techniques et le mème répertoire.

Lorsque le moule était décoré, découpé, séché et cuit, le potier l'emplissait d'argile en appuyant fortement pour bien la faire pénétrer dans les creux. Il lissait la surface de la terre jusqu'au niveau des bords du moule, dont la profondeur était prévue pour donner l'épaisscur du manche. Dans le même moment, le potier tournait la panse de la casserole comme un bol imitant assez bien par son fond concave le profil des ustensiles de métal. Mais ses coups de main habituels se retrouvent dans la moulure supérieure : sur les trois exemplaires complets du musée de Clermont-Ferrand $\left(n^{0 s} 9,9\right.$, 10), le bourrelet rond est analogue à celui du forme 37 contemporain.

Une fois le retrait de l'argile assez grand pour sortir le manche du moule, et la panse assez sèche, le potier ajustait les deux avec de la barbotine. On conçoit la fragilité de l'assemblage, en raison du poids de l'appendice, plus épais souvent que la paroi de la panse. On palliait un peu cet inconvénient par l'adjonction d'un onglet vertical sous le collage. Pour que l'ensemble résiste mieux à la cuisson, il semble que les potiers aient placé parfois un support temporaire sous l'extrémité du manche. En effet, le dos des manches nos 10 et 28 est marqué par un arrachement sans vernis, trace d'un contact qui s'est produit dans le four. Les deux points les plus fragiles de ces manches sont le milieu de la tige et le collage à la panse, comme nous le montrent les cassures des documents retrouvés. 


\section{ATTRIBLTION HE IATATION}

Il semble qu'une prudence assez grande doive etre observée actuellement pour l'attribution des manches de patiere à des potiers connus, a des ateliers localises et à des périodes exactement définies. Le petit nombre de décors. l'absence d'ores, comme la découverte de potiers nouveaux aes dernières années, rendent contestables des conclusions hàtives. Certains documents, certes, sont d'origine assurée : ceux que nous avons trouvés,

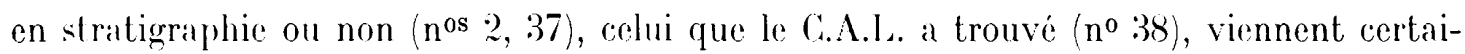
nement de Lezoux; le $\mathrm{n}^{0} 27$ est certainement de Toulon-sur-Allier, où nous avons découvert les productions de DOCCILS ; le $\mathrm{n}^{0} 25$, de Vichy (affirmation .J. D.). Mais un grand nombre provient de collections. On peut certes admettre que les collections Plicque et Fabre-Ollier proviennent en très grande majorité de Lezoux, la collection Rambert, de Vichy, mais il "st certain que des échanges, des achats ont été effectués par ces chercheurs. Le musée de Moulins s'est enrichi de plusieurs collections anciennes, confondlant les produits des ateliers de Toulon-sur-Allier, Vichy, Lezoux, Les Iartres-de-Veyre, et les quelques indications manuscrites sur les objets ne sont pas toujours assurément exartes. Seules, des analyses d'argile pourront différencier avec certitude les origines.

Le transfert de moules et de céramiques d'un site à l'autre à la période antique est aussi attesté. Cela nous rend difficile par exemple, l'attribution à Vichy ou à Lezoux des doruments $n^{\text {os }} 3,4,34$, qui sont certaine $n$ ent du même artisan potier, en raison des motifs irlentiques et bien particuliers qui les décorent. Le moule no 4 porte à l'encre la mention "Vichy"; le manche no 34 provient de la collection Plieque, de Lezoux : il est possible qu'un potier de Lezoux ait fourni en moules de manches un atelier comme celui de Vichy mais les indications que nous avons ici sont trop floues pour en tirer une conclusion.

Il n'en reste pas moins que le nombre de potiers qui ont fabriqué des manches de pateres semble asse\% réduit, selon l'inventaire actuel. Parmi les documents répertoriés, les plus anciens nous paraissent dater de la première moitic du II $^{\mathrm{e}}$ siècle $\left(\mathrm{n}^{0 \mathrm{os}} 9,10,11\right.$, $12,13,16)$; une autre série se situe dans le milieu et la deuxième moitié : les manches de Toulon-sur-Allier et de Vichy, les $n^{\text {os }} 18,19,20,21,22,23,26,28,29$, ainsi que les manches gravies nos $37,38,39$. Ainsi, la période de production de ce lot de manches de patère se place entre 110 et 180 ; Lezoux restant, de loin, le plus grand producteur.

\section{LE DESSIN}

Un certain nombre de manches portent la trace d'un dessin tracé à main levé dans le moule : pétioles de feuilles (nos $15,16,17,32)$; vrille de vigne $\left(\mathrm{n}^{\circ} 17\right)$; sarments ( ${ }^{\text {os }} 7$, 8) ; lignes ondulées terminees on acestées de points (nos 28, 30). Ces facons de faire se rencontrent sur les vases forme: 37.

Le moule $\mathrm{n}^{0} 7$ a ité imprimé avec un prototype décoré de traits obliques, de feuilles et de grappes tracées avec une gouge, et de tiges dessinées avec une pointe mousse. Les 
coquilles ont été imprimées ensuite dans le moule avec des matrices. Il est à noter que le décor par enlèvement de lamelles d'argile aver une gouge se retrouve sur des mortiers fm. 45, dont la fabrication est bien datée du milieu du $\mathrm{II}^{\mathrm{e}}$ siècle.

Les trois manches nos 37,38 , 39) sont plus originaux. Le dessin a été tracé au trait, puis souligné de hachures, dans le fond du moule. Nous avons aussi de très rares fragments de fm. 45) décorés de cette façon; nous en donnons un exemple, sur lequel on voit un animal courant vers la gauche, malheureusement très amputé. Le bord des pattes est traité de la même façon que les jambes, les bras et le torse de Vénus. Ces excisions dans le moule ont donné des reliefs sur le manche. La manière identique de traiter les mains, les vrilles de la vigne, etc. nous font supposer que c'est le même artisan qui a dessiné les trois sujets. Cette technique se développe dans la seconde moitié du $\mathrm{II}^{\mathrm{e}}$ siècle, et date ces documents.

Les motifs : Vénus, Amour, panthère ne sont pas des copies serviles de poinconsmatrices. Certes, les sujets ne sont pas originaux, mais ils nous montrent qu'il existait à Lezoux des hommes habiles à reproduire d'un trait assuré les figures qui ont leur correspondant moulé. Ainsi la panthère est proche de celle qui est imprimée sur une oreille de patere, les Amours vendangeurs ne sont pas rares, ni les Vénus. Mais ces dessins ont une autre sève que les reliefs indéfiniment surmoulés. La composition la plus originale est cette Vénus (no 37) qui pose son pied sur le cou d'un monstre marin, sous lequel court un sarment terminé par des vrilles.

On peut regretter que ces compositions n'aient pas eu une vogue plus grande che\% les potiers, car elles nous auraient restitué un art populaire, que l'arrangement des poinçons exprime, certes, mais d'une façon voilée et bien peu explicite.

\section{INTERPRÉTATION DFS DÉCORS}

1. - VENIS, . HMOT R (manches nos 9,9 bis, 10, 12, 25, 37, 38) : il semble en effet que nous puissions associer a celte scrie la femme nue du no 25 , qui rappelle un type de celte déesse en terre cuite blanche. On sail que Vénus est une des figures les plus souvent reproduites, nolamment sous la forme de l'Anadyomene, par les producteurs de figurines de la vallée de l'Allier. Dans la religion populaire gauloise, elle est en rapport avec le culte des eaux et de la fécondité. Parfois, elle est associée a un dieu barbu qui semble la tirer du sol d'une main, et qui brandit de l'autre une roue (on a vu dans ce groupe une illustralion du dieu de la foudre suscilant la pluie, du dieu du ciel en rapport avec l'eau. Ce dieu du ciel est aussi mis en rapport avec un dieu chtonien. barbu et moustachu, un anguipède ou un triton. dans des représenlations arvernes). Sur 4 exemplaires (n ${ }^{0 s} 9,9$ bis, 12 . 10 probable). Vénus est debout sur un socle assez mince qui la sépare d'un masque masculin de face. Tres tot, celle association s'est faite rhez les fabricants de sigillée, des l'apparilion de ces motifs dans leur répertoire, pourrait-on dire, au début du ${ }_{1} \mathrm{e}$ siecle.

I.es manches non imprimes, mais dessinés, nous revelent peut-ètre une expression plus spontanée de la mentalite du potier : Vénus se dresse sur un animal marin, analogue à ces lritons déformés de la sigillée, el. sous ce monstre, sonl dessines des pampres (no 37); l'Amour est figuré la main sur des pampres, au-dessus d'un cratere.

sur lin manche exceptionnel par sa laclure rustique. fabrique a Virhy raisemblablement ( $\left.n^{\circ} 25\right)$, Déchelette avait cru voir " la scene populaire du satyre decourant une nymphe endormie" (J.D., p. 308;. Le personnage nu, les bras levés, a jornements en sisposés autour de lui. Il semble 
en brandir un de ses deux mains; ils nous rappellerait plutòt la figurines du Chatelete ${ }^{8}$. qui nous montre un Jupiter gallo-romain, brandissant le foudre et appuyé sur la roue, portant une série d's a son bras. Ici, ils tombent tout autour de lui, et une Vénus est, figurée couchée ì terre sur deux de ces $\mathrm{S}$.

Les potiers arvernes ne représentaient pas toujours Jupiter barbu, comme nous en avons notamment un exemple sur un pendentif en sigillée ${ }^{9}$; ils figuraient les scines avec les personnages que leur fournissait un répertoire surmoulé ou copié sur la bimbeloterie hellénistir(o-romaine. sans guere se soucier du sens primilif des motifs, comme l'avait déja remarqué J. Déchelette. Il est, donc, difficile de saisir le sens de ce qu'ils ont representé, mais ici l'association de rosaces, du personnage entouré de $\mathbf{S}$, de la Vénus, est assez curieuse pour que nous la signalions.

Vénus, représentée ou évoquée par l'Amour sur sept manches, est done en rapport ici avec la végétation : feuilles, palmes, pampres, grappes, el avec l'eau (monstre marin/, peul-être aussi avec un dieu chtonien (masque).

2. - MERCL RE. Un seul manche $\left(\mathrm{n}^{0} 15\right)$ parail lié a ce dieu ; à la base du carlurée. des feuilles. Dans les figurations populaires, cet altribut est parfois representé reposant sur le sol.

3. - La femme drapée, qui est peul-itre à l'origine une Victoire $\left(\mathrm{n}^{\mathrm{os}} 24,29\right)$ mais n'en porte pas les altributs, évoque peut-itre une déesse mire, représentalion trís courante che\% les potiers. toujours vêtue d'une tries longue robe.

4. -.- B.lCCIIUS est présent par sa panthère, qui s'élance vers un cep, reconnaissable it ses vrilles $\left(\mathrm{n}^{\circ} 39\right)$; par Silene jouant de la double llute ( $\mathrm{n}^{\text {os }} 18.19$ et 20 ), associé aux oiseaux, aux raisins et aux crateres ; par des pampres $\left(\mathrm{n}^{\text {os }} 7,16,17\right)$ et par une simple feuille de vigne $\left(\mathrm{n}^{0} 3\right)$.

5. - PAN est figuré deux fois, jouant de la syrinx ( $\left.\mathrm{n}^{\mathrm{os}} 1: 3 \mathrm{et} 14\right)$. associé au bouc et au bélier : et son masque, sur les manches $n^{\circ} 21,22,23$ est associé deux fois à un chien courant; sur le $n^{0} 28$. il se trouve placé au sommet d'une colonne.

6. - HERCULE, comme Pan, est associé au chien courant vers la droite. Les autres décors sont de feuilles et de rosaces.

Les décors des manches de patère, en résumé, ont trait à la fécondité des champs, à la végétation, comme aux animaux d'élevage (bélier, bouc, colombes). Les représentations divines, sur ces manches de patere arvernes et sur les manches de patère métalliques étudiés par II me Tassinari, sont assez différentes. Vingt et une de ses patères sont ornées d'un décor qui évoque Mercure, Athéna ou Apollon ${ }^{10}$, et nous n'en avons qu'une avec un caducée, et aucune pour les deux autres divinités. Dans les récentes découvertes de l'atelier de potiers de Gueugnon, sur six pateres signalées, quatre portent Mercure ou ses attributs. Il semble trop tòt pour tirer des conclusions de répertoires aussi fragmentaires mais on peut déjà supposer qu'une des raisons de ces différences pourrait tenir à la date plus ancienne des documents de la vallée de l'Allier.

Quelle est l'utilisation de ces casseroles d'argile? Ieur emploi culinaire n'est certes pas impossible mais leur fragilité rendait cette forme de céramique bien peu fonctionnelle. Il semble plutôt que les potiers les aient fabriquées a une fin cultuclle. Nous avons donné

8 S. ReINaci, Bronzes figlurés de la Gaule romaine, 1894, p. 33, n०5.

9 H. Viktw, Pendentif en sigillée trouvé ì Lezon.c, un nouvean Jupiler (à lungmipeide?), dans Rev. arch. du Centre, VI, 1967, p. 305-310. 
le seul manche trouvé hors de la série arrerne $\left(n^{\circ} 37\right)$, a Alise-Sainte-Reine, au milieu d'une masse énorme de céramique. Décore d'une corbeille qui pourrait suggrerer la récolte: esperée des fruits de la terre, il porte, gravé apres cuisson, une dédicace a Apollon.

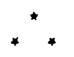

Ce premier repertoire des manches de pateres gallo-romaines an argile nous mont re que cette production a utilisé les mèmes techniques et le mème style que les bols moulés sortis des ateliers de la vallée de l'Allier. Ces objets ne sont pas des surmoulages de patereses en bronze ou en argent mais des imitations habiles, souvent fidèles dans leur forme plus que dans le choix des motifs décoratifs. Les modèles métalliques étaient donc ceux que les potiers pouvaient voir à leur époque, dans leur région, et certainement pas quelques. exemplaires qu'ils auraient conservés, pour rn surmouler les manches. Les pateres qu ils avaient sous les yeux avaient-elles été fabriquées récemment? Cela dépendait evidemment de la proximité ou de l'éloignement des fabriques, que nous ne savons encore situer, des courants commerciaux, de la richesse de la vallée de l'Allier. Il est certain que CalermontFerrand etait une ville active" comme Vichy, en mème temps que les ateliers céramiques. arvernes étaient florissants. Sous pourrions done avoir ici un repère chronologique qui nous indiquerait la période de certaines modes, variables, dans la forme des manches de patiere.

Les plus anciens documents de notre série ne remontent pas au delà du début du $\mathrm{II}^{\mathrm{e}}$ sièce, et il ne serait pas étonnant que cette fabrication ait été ici un apport lyonnais ${ }^{12}$. comme les gourdes, les lampes, les vases à appliques. Ensuite, pent-être les modeles sre sont-ils répétés, enrichis d'apports successifs comme le furent les atcliers aux-mèmes. apports dont nous ne pourons pas encore situer la date, lorigine et le contenu de facen précise, mais qui sont attestés all moins au milieu du II siècle.

Une seconde eturle, qui comprendra les oreilles de patère et les anses d'oenorhoé nous permettra de préciser, pour les documents di-dessus comme pour de nouveaux, des rapprochements avec des modèles métalliques dont les formes d'argile ne sont que les surcédanés habiles et peu coùteux ${ }^{13}$.

\section{Hugurs Virtet.}

10 S. Tassixari, art. cilé, p. 15:2.

11 P.-F. lourvin, Essais sur les origines de Clermont, dans . Vonvelles recherches sur les origines de Clermont-

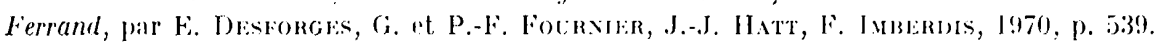

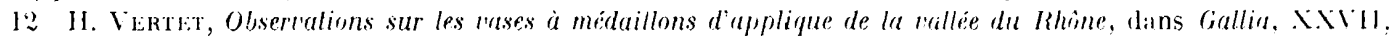
p. $93-133$.

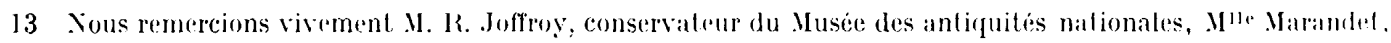
conservateur des Musées de Clepmont-Ferrand, IIme Fonceré, conservitenr du Musé de Moulins, Mr le (iall. conservateur des Museres a Alise-Sainte-lieine, et M. Souchon, d'avoir bien voulu nous autoriser a publine des documents de leurs Musées et de leur collection, et de nous avoir tonne foulas facilites pour les ibluditr. dessimer, photographier. Phofos at dessins de cet anticle sont de II. Virlet. 